\title{
SOBRE LAS CONSTRUCCIONES LOCALES EN ESPAÑOL
}

\author{
JOSE LUIS CIFUENTES HONRUBIA \\ (Universidad de Alicante)
}

\section{Problemas de actancia y circunstancia.}

Generalmente solía admitirse que todo verbo se puede ver acompañado por un complemento llamado circunstancial. Buyssens (1975: 34-35) señala que esto es debido a la identificación del complemento con el referente, al expresar una circunstancia que puede ser local, temporal, etc. Sin embargo, el referente no puede determinar si el complemento es un objeto o un complemento circunstancial. Es preciso renunciar a las consideraciones extralingüísticas referenciales y basarse en hechos lingüísticos.

"Ce qui distingue le complément circonstanciel de l'objet, de l'attribut el du complément d'agent, c'est la notion de régime: le complément circonstanciel n'est pas régi par le verbe; le verbe n'impose pas une phrase comme 'à Paris, j'irai à la Tour Eiffel', la base 'irai' réclame un objet indirect, qui est ici 'à la Tour Eiffel', le complément 'à Paris', n'etant pas régi par la base, est un complément circonstanciel. Par contre dans 'J'irai à Paris' le complément 'à Paris' est un obj̣et indirect." (Buyssens, 1975: 34)

Esta distinción, en definitiva, recuerda la noción de 'régimen' o 'rección', que, desde Bréal o Bally a las propuestas de la Gramática Generativa de ámbito chomskyano, ha permitido distinguir estructuras transitivas de intransitivas. Busse y Dubost (1977), desde la perspectiva de una teoría de la valencia, distinguen un tipo de adverbios de lugar o dirección regidos por el verbo. Igualmente, Happ (1978: 121) y Martinet (1984: 198-218) hablan de 'complementos conjuntos' y 'complementos disjuntos' o 'funciones específicas' y 'funciones no específicas' (aunque, en este caso, no se apliquen adecuadamente a las construcciones locativas, como ocurre también con Dik (1981) y sus funciones centrales y periféricas o satélites).

Dervillez-Bastuji (1982: 265-274) señala que un verbó como 'ir' no puede construirse, en su sentido local, sin una expresión locativa: la localización no es un constituyente facultativo. Es por ello que distingue dos tipos de complementos locativos: unos, fuertemente regidos por el verbo ya que pertenecen a su combinatoria sintáctico-semántica, siendo constituyentes del sintagma verbal y repartiéndose en dos clases los verbos así subcategorizados por las expresiones locativas: estáticos y de desplazamiento. Otros, 
periféricos, facultativos y móviles, que no dependen del sintagma verbal y son auténticos "adjuntos" a la frase, son los llamados por Boons, Guillet y Leclère (1976: 216) 'complementos escénicos'. Estos complementos de lugar escénicos no dependen del verbo, sino que son analizados como un complemento de la frase $o$, al menos, de una estructura jerárquicamente superior al sintagma verbal.

Steinitz (1969) distingue dos tipos de adverbios o adverbiales, según se trate de un constituyente obligatorio del verbo, del que determina la subcategorización, o sea un complemento libre y facultativo del verbo, sin influencia sobre su subcategorización ni dependencia de esta subcategorización.

G.Helbig y Schenkel (1969) distinguieron entre 'complementos' e 'indicaciones', según vengan referidos a toda la oración (Angaben) o sean regidos por el núcleo predicatorial (Ergäzungen). Los complementos podían subdividirse en obligatorios y optativos mediante la prueba de la eliminación: si un complmento era eliminado y la oración subsistía correspondía a un complemento optativo. Los mismos autores -al igual que Steinitz (1969)- propusieron también la prueba de la vuelta atrás para delimitar entre complementos obligatorios y opcionales, que consistía en la reformulación del elemento en cuestión como expresión incrustada en otra: si resultaba una expresión gramatical y sin cambio de significado se trataba de una indicación, en caso contrario, complemento. Sin embargo, esta prueba mostraba múltiples irregularidades e inconsecuencias.

A.Schönfeldt y B.Zander-Lüllwitz (1976) trataron de delimitar las características de los complementos obligatorios y optativos o facultativos. La obligatoriedad vendría dada porque su ausencia a) viola la gramaticalidad de la oración; b) da lugar a un significado distinto de la oración. Los facultativos vienen caracterizados porque a) están dados en el cotexto o contexto; b) en determinadas construcciones, ciertos actantes son supuestos ya léxica ya conceptualmente; c) hablante y oyente son conscientes de que un papel queda sin cubrir.

V.Engel y H.Schumacher (1976) distinguen complementos de indicaciones no según criterios de necesidad u omisión, pues estos factores dependen de fenómenos comunicativos, no sintácticos, sino que distinguen ambos elementos según se trate de un elemento específico del verbo o de uno libre añadido.

Happ $(1977 ; 1978)$ distingue entre complementos e indicaciones libres, siendo el test de reducción de la oración el que permite identificar un actante como obligatorio. El carácter marginal de los circunstantes, la posibilidad de separarlos de la oración, se revela por la utilización de un proverbo como "facere". Dado que facere puede ser considerado como un proverbo, una especie de anafórico verbal con carga semántica casi nula, puede ser sustituido por cualquier verbo: si la oración, tras la inserción de "et id facit", sigue siendo gramatical, el elemento aislado será un circunstante; será actante si la oración se convierte en agramatical. Sin embargo, la evidencia de este test es muy discutible.

Herbst (1984) añade otra prueba o método para identificar los complementos obligatorios y optativos: en expresiones interrogativas son sustituíbles por "quién", "a quién", "qué", mientras que esta sustitución no es posible con indicaciones libres. Sin embargo, obviamente, este análisis no nos permitiría dar cuenta de los casos de localización actancial, por ejemplo.

M.Rothenberg (1986), frente al sujeto y los complementos obligatorios y optativos, delimita los complementos de frase, caracterizados por su capacidad de traslado al principio o final de frase, modificándola en su totalidad, y los complementos circunstanciales libres, que no son "libres" totalmente, ya que existen restricciones semánticas a su aparición, y pueden no realizarse en la frase. Los complementos facultativos locales se diferencian de los libres locales por una absoluta inmovilidad. 
H.L.Somers (1984) -a juicio también de V.Báez (1988: 86-87)- es quizás el autor que mejor ha distinguido complemenos de indicaciones. Así, diferencia entre 1) complemento integral, que en ninguna construcción puede ser sustituido; 2) complemento obligatorio, que es obligatorio al menos en una construcción; 3) complemento opcional, que puede ser eliminado sin variar el significado del núcleo predicatorial de la oración; 4) complementos medios, que pueden ser eliminados pero no pueden acompañar a cualquier predicado; 5) adjuntos, que son siempre eliminables y pueden ir con cualquier esquema predicactancial; 6) elementos extraperiféricos, determinan toda la oración.

Savary (1984: 76-87, 236-239) señala que es muy difícil la delimitación entre actante y circunstante: parece tratarse más de una graduabilidad o jerarquía en el grado de ligazón entre la base verbal y los constituyentes que de una distinción fija y delimitada; es por ello que Savary habla de intervinientes: diversas entidades que "intervienen" en la situación evocada por el enunciado y cuya expresión lingüística puede estar más o menos ligada al empleo del verbo-predicado en el enunciado. Los intervinientes se encuentran determinados ad hoc para una situación concreta o un grupo de situaciones ligadas por la práctica, y no pretenden tener una validez general, sino que están limitados a la situación a partir de la cual han sido aislados. Savary realiza una división de cuatro tipos de intervinencia, con lo que evita el binarismo actante/circunstante.

Hopper y Thompson (1980) entienden la transitividad como una relación que se obtiene a través de una cláusula. Es una propiedad global de las cláusulas, establecida a partir de una serie de rasgos basados en el discurso, especialmente en la distinción entre elementos centrales y marginales -de naturaleza eminentemente pragmática-. Las propiedades semánticas y gramaticales irrelevantes para la "centralidad" lo son también para la transitividad. La transitividad así entendida no es algo dicotómico, sino un continuum en el que es posible observar una graduabilidad. Para casi todos los lingüístas el grado de transitividad es un continuo (Cano Aguilar, 1981:28), pero no se trata de que el lexema verbal sea concreto o necesite de precisión, sino que hay que ver si la estructura lógico-conceptual de su predicación (en el sentido de marco o esquema como modelo cognitivo) necesita determinados elementos. El gradiente de esa necesidad determina las relaciones actanciales y circunstanciales en la manifestación lingüística, lo cual evidencia la interdependencia sintáctico-semántica, propia de los hechos de lengua, en la transitividad (Blinkenberg, 1960: 7).

Lakoff (1987: 289-292, 462-468) distingue un tipo de modelos cognitivos llamados "simbólicos", caracterizados por la asociación de elementos lingüísticos con elementos conceptuales. Estos modelos, con una estructura radial basada en una teoría prototípica de las categorías, afectan tanto a los lexemas (lo que explicaría el fenómeno de la polisemia, por ejemplo) como a las categorías y construcciones gramaticales. De esta manera, podemos interpretar la rección verbal como un esquema en el que la categoría central o predicado se encuentra más o menos ligada a determinadas estructuras actanciales. Este más o menos permite la distinción "borrosa" entre actante y circunstante.

En el ámbito hispánico, la dialéctica actante/circunstante ha sido muy prolija, aunque subsidiaria de las nociones de transitividad e intransitividad (Alarcos, 1981; Cano Aguilar, 1981; Martínez García, 1986; Báez San José, 1988, entre otros). Martínez García (1986: 112-119) recoge (Alarcos, 1981) la existencia de ciertos aditamentos que tienen gran cohesión semántica con el lexema verbal, así "ir a X" o "venir de X". Es por ello que Martínez García llega a hablar de "fronteras borrosas" entre suplemento y aditamento. Frente al carácter marginal que generalmente presentan los aditamentos, los suplementos mantienen una relación mucho más estrecha con el núcleo del predicado, salvo cierta clase de aditamentos "difícilmente suprimibles en la oración, so pena de que se produzca una 
secuencia cuando menos incompleta en su sentido"; se trata de ejemplos locales como los ya señalados.

Según Martínez García (1986), no hay un criterio único y concreto para diferenciar suplemento de aditamento, con los complementos locativos que venimos comentando. Pese a ello, se esfuerza en una distinción según su referencia sea física o abstracta, con lo cual, lo que demuestra el trabajo citado es que no hay razón suficiente para distinguir como funciones distintas -salvo la referencia- el suplemento y las expresiones locativas que venimos considerando como actanciales (aunque con un funcionamiento peculiar -Rojo, 1985: 181-188-, que podemos condensarto en su centralidad o no prescindencia, la posibilidad de ir encabezado por varias preposiciones alternantes, la sustitución adverbial y su significado locativo; de ahí que algunos autores propongan una nueva función: Happ, 1977: 350-353; 1978: 105-106, 121-123; Rojo, 1985: 188).

Cano Aguilar (1981: 81-95) es mucho más claro a este respecto, y reconoce como transitivos determinados verbos de movimiento y verbos con objeto de lugar. Tanto Cano Aguilar como Martínez García y Gutiérrez Araús (1987), retomando lá idea de Blinkenberg (1960), aceptan como sintáctico-semánticos los criterios caracterizadores de la transitividad. La transitividad será una relación sintáctica que supone una función semántica entre el verbo y uno o más complementos (Cano Aguilar, 1981: 31 ). La ausencia de un paralelismo total entre forma y función transitivas hace que sea posible hablar de una transitividad directa e indirecta (o preposicional, como prefieren denominarla Cano Aguilar y Gutiérrez Araús), cuyas diferencias radicarán más en el plano formal que en el semántico. Igualmente, Alarcos (1981) rompe la oposición transitivos/intransitivos, e indica que sólo existen diferencias en la estructura del predicado (los circunstantes no serían elementos integrantes del predicado, sino complèmentos de la oración entera). Alarcos considera que la transitividad no es un hecho del sistema, por tanto la distinción entre los dos tipos de construcción hay que buscarla en el plano sintagmático. Una función semántica será central o marginal según el tipo de predicado; pero el reconocimiento de tales estructuras sólo es factible en el discurso (Hopper-Thompson, 1980: 251). Según Rojo (1983: 83) una función semántica será central o periférica según el tipo de predicado (las funciones sintácticas serán la manifestación formal de las funciones semánticas, y no tiene por qué haber una correspondencia biunívoca entre ellas); pero las funciones (1983: $87 \mathrm{y}$ ss.) no deben ser concehidas individualmente, ya que, al presentarse siempre formando parte de esquemas, hay que dar preferencia al esquema funcional sobre la función aislada. Es por ello que se necesita un planteamiento textual e integral, sobre todo si se quiere caracterizar un determinado grupo de verbos -en oposición a otros- por su descripción sintáctico-semántica.

G.Rojo (1983: 96-97; 1985) ha recordado el cajón de sastre en que a veces se ha convertido el complemento circunstancial, al haber introducido en él -como en el adverbiotodo lo que no encajaba bien en ningún lado. Los trabajos de Rojo fundamentan nuestra tesis en el sentido de que plantean que hay que diferenciar un grupo de aditamentos, los locales -no hablaremos ahora de ciertos complementos, llamados circunstanciales, de medida, peso, etc.- que, en deteminadas construcciones no resultan marginales al predicado. Rojo, debido a la peculiaridad funcional de estos elementos respecto a los suplementos, considera que no es adecuado llamarlos suplementos y propone el término 'complementos adverbiales', en espera de una mejor denominación (Alarcos ha hablado de 'suplemento inherente'), pero señalando su carácter nuclear respecto a la predicación, es decir, su función actancial.

$M^{a}$.L.Gutiérrez, en un interesante trabajo sobre la transitividad preposicional (1987), comenta su interdependencia sintáctico-semántica. La transitividad es vista como una 
particular cohesión que conduce a la noción de rección, y afirma, remontándose a Blinkenberg, que esta transitividad puede ser directa o indirecta, aunque esta última denominación, por la confusión que puede acarrear, prefiere sustituirla por la propuesta por Cano Aguilar de "transitividad preposicional", y es ello lo que le lleva a hablar de 'complementos de régimen preposicional' (1987: 370) ', que acogerían, entre otros, a determinadas expresiones localizadoras con verbos que las necesitan, es decir, que hay determinadas estructuras de predicado, con "residir" o "proceder" por ejemplo, que desarrollan una expresión localizadora en función actancial.

E.Ramón Trives $(1975 ; 1979 ; 1982)$, a propósito de los problemas de actancia y circunstancia, ya sean considerables en un ámbito nuclear o internuclear, señala que los criterios de prescindencia o no prescindencia, y algunos otros puramente formales, generalmente el efecto que tienen es crear malentendidos. En consonancia con las propuestas de Savary, Somers y Hopper \& Thompson por ejemplo, incide en la graduabilidad de la prescindencia, desde la motivada por el semismo clasemático del predicante hasta la relativa a su semismo semantemático, al igual que considera los aspectos relativos a su incidencia en el enunciado o la enunciación.

Por otra parte, los llamados "circunstantes" no son comodines que se pueden combinar con cualquier estructura predicativa, sino que deben formar parte de la 'isosemia clasemática'. La isotopía clasemática es el límite del sentido textual, es el minimum exigible para que un texto sea tal.

"La organización clasemática, previamente existente o meramente resultantc, es indispensable, como condición ineludible que todo texto debe cumplir, tanto si los mecanismos de nexuación clasemálica instrumentan determinadas piezas morlosintácticas, como si quedan en lorma de nexuación latente entre las distintas piezas en sintagmación. La diferencia existente entre un "aglomerado de palabras" y un lexto -desde un diccionario al más logrado poema-, en cualquier caso, debe huscarse en la estructura clasemática genotextual previa o fenotextual resultante." (E.Ramón Trives, 1982: 187)

Igualmente, y debido a su composición isosémica, su prescindencia no es totalmente inocua. Desde una perspectiva remática, los tradicionales circunstantes tienen una fuerte carga de información semántica (H.Contreras, 1983); información semántica que está clasemáticamente isosemizada con el resto del esquema predicactancial y que desde una perspectiva macrotextual es obligado punto de consideración en la aserción de la frase, pues ésta constituye una declaración relativa al conjunto del enunciado, donde todos sus elementos funcionalmente pertinentes tienen una función actancial en tanto 'intervinientes' en el proceso discursivo.

Se ha señalado que en el nivel noemático no hay posibilidad de establecer límites entre actante y circunstante (K.Heger, 1976); es sólo en el ámbito de cada lengua concreta donde pueden darse las especiales motivaciones para la delimtiación. El nivel noemático puede ajustarse a una lengua dada, siendo por tanto particular, o puede aplicarse al funcionamiento de distintas lenguas, siendo entonces general (Ramón Trives, 1982: 173189).

Trives considerará actante todo aquel elemento exigido de forma específica por el semismo del verbo en cuestión en un determinado esquema predicactancial. A su vez, será considerado circunstante aquel elemento exigido al menos de forma genérica por el semismo del verbo considerado. Así pues, semantema y clasema -núcleo sémico y base

- Ya en un lundamental trabajo anterior (Cutiérrè Araús, 1978: 166-169) entendía como actanciales determinadas construccions de régimen preposicional. 
contextual- parecen ser los instrumentos necesarios para la delimitación de la actancialidad o circunstancialidad, ya sea en su consideración nuclear o internuclear. Es esta la distinción que permite a Trives establecer la fundamental delimitación entre 'verbos locales' y 'localizables'.

Así, en la oración "Juan habita en Madrid", "en Madrid", considerando to anteriormente expuesto, no puede ser entendido como circunstante, ya que el verbo "habitar" necesita específicamente un complemento local, siendo considerado por tanto dentro de la categoría de actante. Igual ocurriría con otra serie de verbos como 'ir', 'venir', 'alojarse', etc., donde el carácter loćal del verbo necesita y exige un complemento local. Nunca puede ser concebida de forma aceptable una oración como "*voy" o "*vengo" -en su sentido local-, que es impensable si no está dada sintagmática o co(n)textualmente la localización; es decir, el semismo del verbo "ir" necesita específicamente un complemento local, frente a otro tipo de verbos donde ya hemos dicho que esta necesidad es tan sólo genérica o de coherencia clasemática.

Así pues, llamaremos verbos locales o locativos ${ }^{2}$ a aquellos cuyo semismo exige específicamente -en un determinado esquema- un complemento local, que será considerado actante (coincidiendo con la propuesta de Boons (1988: 3-4). Verbos localizables serán aquellos que tan sólo suponen de forma genérica o clasemática un complemento local, siendo considerado en este caso circunstante. Al primer tipo pertenecerían los verbos del grupo de 'ir', 'venir', 'habitar', etc., cuyo complemento local funcionará actancialmente, necesitándose igualmente un nombre con que bautizar a este tipo de complementos, y que puede ser el de suplemento inherente, complemento adverbial, complemento de régimen preposicional o suplemento local, aunque las tres primeras denominaciones no sólo acogen a los locales -resultando la primera también redundante-, y la última señala un funcionamiento diferente respecto a los suplementos.

V.Báez (1988: 87-88), ampliando las propuestas de Somers, ha distinguido las siguientes funciones sintagmáticas de la oración: 1) sujeto, que no es complemento, y es determinado indirectamente a través del núcleo predicativo por todos los complementos; 2) complemento integral, que es determinador del núcleo predicativo y no puede ser sustituido por otro, ya que determina de manera necesaria ya sea al núcleo predicativo, o a la eventual relación establecida entre sujeto y núcleo predicativo; 3) complemento obligatorio, que si bien puede ser eliminado en alguna diátesis construccional de la oración, al menos en una es obligadamente necesario; 4) un tipo de complemento obligatorio que puede ser ulteriormente determinado por otro complemento con idéntica función sintagmática; 5) complemento medial, que es facultativo, pero que puede diferenciar tipos de nociones; 6) adjuntos, funciones sintagmáticas siempre eliminables y que no distinguirían esquemas oracionales, y 7) elementos extruperiféricos.

V.Báez señala que el sujeto, los complementos integrales, obligatorios, obligatorios ulteriormente delimitables y mediales son necesarios para la delimitación de las clases de esquemas oracionales (observándose, evidentemente, una graduabilidad en su aparición), mientras que los adjuntos son meros índices fenomenológicos, explicables en el caso de la localización porque toda enunciación está localizada. Los elementos extraperiféricos determinan toda la expresión, entendiéndose como índices de conexión entre las distintas expresiones textuales, o como manifestación de la posición del hablante respecto a la totalidad de la expresión.

2 Agradezco al Dr. Estanislao Ramón Trives la idoncidad de la denominación de "locativos", en lugar de "locales", que parece responder mejor a la línea de trabajo que venimos siguiendo. 
Así pues, un verbo locativo será aquel que desarrolle un complemento local necesario, mientras que un verbo localizable será aquel que tan sólo desarrolle la localización en forma de adjunto o elemento extraperiférico.

\subsection{Organización temático-remática.}

H. Contreras, en su interesantísimo libro sobre el orden de palabras en español (1983), establece la siguiente jerarquía remática:

1. Instrumento, adverbio de modo, adverbios 'fuertes' (de tiempo o

de lugar).

2. Destinatario.

3. Complemento, locativo, temporal, procedencia, beneficiario, identificador.

4. Paciente.

5. Adverbios 'débiles' (de tiempo o de lugar).

H.Contreras, 1983: 83.

Esta división casuística en tres tipos de expresiones localizadoras: adverbios fuertes, débiles y locativos (agrupamos en este punto al conjunto de expresiones de contenido local incorporadas en el punto 3 de su esquema), resulta poco clara, principalmente porque apenas delimita unos casos de otros. La única caracterización que parece efectuar de manera funcionalmente pertinente es la de adverbios 'débiles'. Estos adverbios débiles son elementos marginales potencialmente remáticos y constituyentes inmediatos de la oración, que tienden a aparecer en la porción temática de la oración, sirviendo, fundamentalmente, para situar la parte más informativa de la oración proporcionándole un marco de referencia (ej: "En Murcia, fui a casa de Pedro para saludarle, pero no me quiso abrir"), se corresponderían con los elementos extraperiféricos de Somers y Báez. En estos casos se trata de localizaciones, siempre de lugar en dónde o Ubi, que afectan a todo el esquema predicacional; son circunstantes en el sentido que enmarcan localmente el proceso discursivo expuesto. Deben ser distinguidos de aquellas otras localizaciones circunstanciales que no indican un marco de referencia, en tanto que dispositivo temático, sino que expicitan una localización del proceso (los adjuntos). Unos y otros se distinguirán por el fuerte contenido remático de los últimos, frente al funcionamiento de organización temática de los primeros que, como señala Contreras, suelen estar dispuestos en la parte primera de la oración, como enmarcador temático de ella.

En cuanto a los adverbios fuertes y el conjunto de los locativos del punto 3 de la jerarquía remática establecida, Contreras no establece medio alguno para poder distinguirlos. Podríamos estar tentados a delimitarlos según los conceptos de actancia y circunstancia, pero el problema es mucho más complejo que esta simplificación.

Al haber defendido, desde una perspectiva noemática del lenguaje, una clase única de locativos espaciales (Cifuentes Honrubia, 1989), considerados como elementos con contenido espacial que relacionan una figura y una base, que pueden ser entendidas terminativa o co(n)textualmente, debemos establecer la vinculación con las expresiones localizadoras espaciales que introducen y fijar una posible sistematización. Desde esta perspectiva noemática, conceptual o meta/prelingüística, que es como podemos sacar al lenguaje de su circularidad (Ramón Trives, 1982: 171), entenderemos las expresiones localizadoras espaciales como un caso profundo que se ve resuelto en español a través de una serie de marcadores casuales -los locativos- que nos dan cuenta de su organización morfosintáctica: preposición, adverbio, prefijo, locución prepositiva. 
Pero si bien estos marcadores se encargan de la organización morfosintáctica de las expresiones locativas, debemos dar cuenta también de la organización semánticopragmática de las expresiones localizadoras, o formas casuales, encabezadas por las marcas casuales. En español debemos distinguir tres tipos de formas casuales: a) expresiones locativas, responden a la tradicional cuestión UBI; b) expresiones locativo-directivas, responden a la tradicional cuestión UNDE-QUO; c) expresiones locativo-extensivas, responden a la tradicional cuestión QUA. Estas expresiones son manifestación de tres organizaciones conceptuales o de tres tipos distintos de modelos cognitivos idealizados (Lakoff, 1987): contenedor-contenido (Ubi), direccionalidad, especificado como origen, meta y sentido (Unde-Quo), y camino (Qua).

Las marcas casuales articularán estas formas casuales según dos factores: 1) el contexto en el que se inscribe el locativo, es decir, la consideración del tipo de objetos que relaciona y el verbo que instruye la expresión; 2) la posibilidad de una marca simple o compuesta, es decir, de un locativo o de una combinación de locativos con un funcionamiento unitario.

La función de una expresión localizadora es especificar dónde está localizado un objeto. Una expresión locativo-direccional describe un cambio de posición, y la denominamos así porque todo desplazamiento implica un cambio de lugar, es decir, un origen y una meta o final, y esto es lo que señala el locativo, siendo su combinación con el verbo la que da cuenta del desplazamiento, pues es el verbo la unidad lingüística encargada de manifestar todo proceso como es el desplazamiento. Desde una óptica noemática del lenguaje, la expresión del desplazamiento en español debe entenderse como un proceso verbalizado por un núcleo predicatorial que pone en relación dos lugares Ubi: un origen y un final, que son dinamizados de tal manera según el semismo específico del verbo en cuestión. Ahora bien, la verbalización o manifestación terminativa de estas formas casuales hace buena la idea de una óptica textual del lenguaje, concebido como interacción comunicativa, pues cualquiera de estos dos locativos (o los dos) puede estar dado co(n)textualmente. De igual forma, el lenguaje es argumentación, es decir, reposa en una intencionalidad comunicativa $y$, en muchos casos, no dinamizamos alguno de los locativos no porque esté dado co(n)textualmente, sino porque no es pertinente para nuestra comunicación. Toda enunciación está localizada, pero no toda enunciación enunciada. Ello dependerá, entre otras cosas, por ejemplo de la pertinencia informativa o del grado de informatividad de lo dicho.

Otro problema es la relación entre las expresiones Ubi y Qua. Nuestra propuesta es que todos los enunciados Qua implican un lugar Ubi. Es evidente que todo lugar Ubi necesita una extensión, pero ésta resulta irrelevante en nuestra comunicación. Ubi y Qua se distinguen por la concreción de uno frente a la indeterminación y vaguedad del otro.

\subsection{Propuestas de clasificación.}

Todo verbo puede ser localizable (tipo Ubi), siempre y cuando se incorpore al minimum exigible de la isosemia clasemática, como límite del sentido textual en tanto que coherencia establecida. Ahora bien, hemos de distinguir los casos de circunstancia temática (elementos extraperiféricos) de aquellos otros en los que la localización Ubi funciona actancial o circunstancialmente pero con un contenido remático fuertemente informativo, y que podría acogerse -aunque no con exclusividad- a los tipos 1 y 3 de la 
jerarquía remática de Heles Contreras ${ }^{3}$. Denominaremos a los casos de localización enmarcadora o temática Ubi-I, frente a los otros casos de localización, actancial o circunstancial, informativamente remática, que serán Ubi-2.

Respecto a las formas casuales Qua, pueden indicar vía o camino, y también señalar extensión indeterminada. Al primer tipo semántico-pragmático lo denominaremos Qua-2, y al segundo Qua-1. La distinción entre estos Qua-1 y los Ubi-2 es muy problemática, y semántico-pragmáticamente muy difícil de delimitar, ya que es precisa una reconstrucción muy detallada del esquema o marco de la escena espacial, e incluso sería necesario una especificación de la teoría de los objetos con que se trabaje. Sin embargo, se pueden encontrar algunas claves para su delimitación; así, la expresión localizadora Qua-1 suele conceptualizarse como un camino, y las marcas casuales de los Qua-1 suelen ser parafraseables o estar construídas con locativos tipo "por" y sus combinaciones.

En el caso de las expresiones Unde-Quo, denominaremos Unde-Quo-1 a las que expresan un complemento locativo siendo el verbo parafraseable por extenderse. Su estructura será similar a la de los verbos direccionales con complemento de dirección, pero el sujeto no es agente ni animado, resultando entonces una construcción que no indica desplazamiento del sujeto, sino extensión o distancia, entendiendo, por tanto, que ese sujeto no animado es predicable en cuanto a su extensión. Ej: "El camino va de La Losilla a Fuenteálamo". Langacker (1988: 69-76) caracteriza los verbos de movimiento como perfectivos, pues señalan el cambio de posición espacial del elemento móvil en función del tiempo. Los verbos estáticos son imperfectivos, pues suponen la continuidad a través del tiempo de una posición estable. Los ejemplos con contrucciones Unde-Quo1 describen unas situaciones estables donde nada es descrito como un elemento móvil o con cambio; la imposibilidad de la construcción "estar + gerundio" del verbo en cuestiòn confirma su análisis como proceso imperfectivo. La dimensionalidad que percibimos en tales frases puede ser atribuída al orden en el que los diferentes aspectos de la configuración son activados. Langacker concluye que, en un caso como el expuesto, un verbo perfectivo de movimiento físico ha desarrollado un valor suplementario, imperfectivo, por el cual describe la continuidad en el tiempo de una configuración estática. La noción de movimiento no ha desaparecido totalmente, quedando un rasgo en la direccionalidad según la cual la configuración estática es conceptualizada. Serán entendidas como construcciones Unde-Quo-2 las que sí articulan un desplazamiento, conceptualizando, por tanto, un término de partida y otro de llegada.

Según hemos expuesto, las expresiones localizadoras Ubi-1 pueden aparecer combinadas con cualquiera de las distintas estructuras predicado-expresión localizadora. La funcionalidad temática de estas expresiones hace que sirvan de marco de referencia a la oración que las acompaña, pudiendo simultanearse con cualquiera de las combinaciones que hemos expuesto en la clasificación anterior.

Las expresiones Qua-2 pueden combinarse con las Unde-Quo-2 tanto con verbos localizables como con locativos:

a. Juan fue a la oficina por el atajo.

b. Juan voló de Alicante a Madrid por la ruta más larga.

En estos casos, la expresión localizadora Qua-2, que es circunstante, es el elemento

3 Al no ser exigida específicamente la localización, cuando se predica circunstancialmente es informativamente muy relevante. 
remáticamente más informativo. Si nos acogiéramos a la jerarquía remática de Contreras, el circunstante Qua-2 tendría el rango 1, mientras que el actante Unde-Quo-2 el rango 3. Las expresiones Ubi-1 -que también pueden articularse con los ejemplos anterioressiempre el rango 6 de Contreras.

El análisis de estos casos, sin embargo, nos lleva a replantear los problemas de actancia y circunstancia, y, en definitiva, la organización verbal que llevamos efectuada.

\subsubsection{Verbos localizables, locativos y semilocativos.}

Hasta ahora habíamos considerado tres tipos de relaciones argumentales con el predicado: el circunstante enmarcador Ubi-1, el circunstante de los verbos localizables y segundo complemento de los direccionales, y el actante. Sin embargo, hay un tipo concreto de verbos localizables que permiten las combinaciones Qua-2 y Unde-Quo-2, resultando, igualmente, una marginalidad o centralidad diferente, sobre todo porque su prescindencia lo que hace es que se altere el esquema significativo verbal. Este tipo de verbos que venimos comentando -como 'volar'-, puede ser predicado en cuanto actividad (modo o manera) o en cuanto desplazamiento. En el primer caso, las relaciones locales que permite son circunstanciales, en el segundo son actanciales, aunque una actancialidad, diríamos, de segundo grado.

En el fondo de toda esta cuestión se encuentran dos planteamientos que creo necesario recordar. Por un lado, Coseriu (1978: 50-79) entiende las categorías como modos significativos del hablar "; lo que debe y puede definirse es un concepto, no los objetos correspondientes a tal o cual categoría, que constituirían la clase. Por otro lado, una teoría de modelos cognitivos de base prototípica (Rosch, 1974; 1977; Lakoff, 1987, por ejemplo) demuestra que la categorización es una actividad que procede seleccionando prototipos, elementos especialmente representativos debido a sus diferencias respecto a los de otras categorías; las clases así elaboradas acogerían también, aunque de forma aproximativa, a otros elementos alejados en mayor o menor grado de las características que definen al prototipo. Aunque Rosch no otorga a este tipo de procesos una funcionalidad universal, el mismo tipo de fenómenos afectaría a categorías diferentes, como las lingüísticas. Así pues, la elaboración de las categorías no siempre es el resultado de un proceso de inducción sobre la realidad; desde una perspectiva prototípica, la categorización es entendida como la selección de prototipos o elementos especialmente representativos, de forma que no todos los posibles miembros de una categoría presentan el mismo grado de pertenencia o participación en una categoría, ya que si bien coincidiendo con el conjunto de rasgos del prototipo, podrán no coincidir totalmente con otros elementos.

Esta visión prototípica nos explica, por un lado, la graduabilidad de la rección verbal en una dinámica actante-circunstante no exclusivista. Por otro lado, el problema de la localización, pues toda enunciación está localizada, pero no toda enunciación enunciada, y dentro de este último tipo podemos ver un gradiente paralelo a la dinámica actancial, que puede verse recogido, por ejemplo, en los distintos complementos nucleares señalados por V.Báez (1988).

Lo que propugnamos, pues, es lo siguiente: hay un tipo determinado de verbos (que

- No pretendo defender una categoría de verbos locales, evidentemente, pero sí, creo, es posible distinguir dentro de la categoría 'verbo' distintos subtipos definidos por una seric de rasgos que les otorgan unas determinadas características y funcionamiento, y que configuran ciertos esquemas predicactanciales. 
llamaremos semilocativos) que no sólo especifican un desplazamiento, sino un desplazamiento de un determinado modo o manera, de forma que necesitan ese tercer elemento que se suele conceptualizar en el desplazamiento, que es el camino o vía. Cuando se construye un predicado con este tipo de complementos se predica la manera o modo del desplazamiento, resultando neutralizados los puntos de llegada y salida. Algunos autores han configurado, desde òpticas distintas, un tipo de verbos similares a los semilocativos; así, Boons (1988) aisla un tipo de verbos que denomina ML, y que informan principalmente sobre la manera en que se efectúa el recorrido o sobre su forma, y el complemento Qua que manifiesta el camino es nuclear (Boons, 1985: 204). Vandeloise (1988: 85) también propondrá un tipo de verbos cuya función es incidir en la manera en que el movimiento se efectúa; frente a los verbos direccionales que describen un desplazamiento evaluado en relación a un sistema de referencia exterior a la figura móvil, los verbos de manera de desplazamiento describen un movimiento del cuerpo evaluado en relación a un sistema de referencia que les está ligado. Pero -como tendremos oportunidad de argumentar más tarde- estos verbos semilocativos, según el discurso, se pueden recategorizar, constituyendo distintos esquemas predicactanciales. Se recategorizan como direccionales si actualizan un complemento Unde-Quo-2, funcionando actancialmente, y, en caso de que aparezca un Qua-2, funcionando este último como circunstante. Y también se pueden recategorizar como localizables si no actualizan ningún complemento local, no haciendo pertinente en este caso ni su dimensión espacial, ni su dimensión direccional, sino, simplemente, predicándose como manera o modo de acción. De ahí que sólo puedan construirse con circunstantes Ubi- 1 .

1. Juan vuela muy bien.

2. Juan vuela por la playa.

3. Juan vuela de Alicante a Murcia.

Así pues, el esquema cuasi definitivo que resulta de todo esto, en el que también tratamos de incorporar su valor remático siguiendo a Contreras, es el siguiente:

A) VERBOS LOCALIZABLES: Ubi-1, Ubi-2, Qua-1. Combinaciones: Ubi-1/Ubi2; Ubi-1/Qua-1. Jerarquía remática: Ubi-1 siempre rango 6; Ubi-2 y Qua-1 rango 1. Es evidente que siempre nos referiremos a un orden no marcado; discursivamente es posible alterar esta jerarquía, como Contreras señala, debido a problemas de énfasis, topicalización o tematización, etc.

4. En Murcia, Juan siempre come en el Rincón de Pepe.

5. En Alicante, Juan ha bailado por todas las discotecas.

B) VERBOS LOCATIVOS: estativos: Ubi-1, Ubi-2, Qua-1. Combinaciones: Ubi1/Ubi-2; Ubi-1/Qua-1. Jerarquía remática: Ubi-1 siempre rango 6; Ubi-2 y Qua-1 rango 3. Es muy difícil delimitar, partiendo de Contreras, la separación de los complementos locativos rango 1 y 3; podemos suponer que cuando estos elementos son circunstanciales, por ser menos obligados son más informativos, pues si no no se dirían; es decir, diferenciaremos los rangos 1 y 3 según se trate de expresiones locativas actanciales o circunstanciales, cuando son actanciales son exigibles por el semismo del verbo y, por tanto, esperables -aunque con un contenido remático fuertemente informador-, cuando son circunstanciales no son necesarias y, por tanto, para no trasgredir las leyes conversatorias de origen en Grice, deben ser informativas, exhaustivas y pertinentes para la comunicación; al no ser necesarias en el esquema predicacional, cuando se enuncian es porque son 
elementos remáticamente muy relevantes. Ejemplos:

6. En Alicante, Juan vive en casa de sus padres.

7. En Murcia, la foto de Felipe está por todas partes.

Verbos direccionales: Ubi-1, Ubi-2, Qua-1, Qua-2, Unde-Quo-1, Unde-Quo-2. Combinaciones: Ubi-1/Ubi-2; Ubi-1/Qua-1; Ubi-1/Qua-2; Ubi-1/Unde-Quo-1; Qua1/Unde-Quo-2; Ubi-2/Unde-Quo-2; Qua-2/Unde-Quo-2; Ubi-2/Qua-2; Qua-1/Qua-2; Qua-2/Unde-Quo-2/Ubi-2; Unde-Quo-2/Qua-2/Qua-1; Ubi-1/Qua-1/Unde-Quo-2; Ubi1/Ubi-2/Unde-Quo-2;Ubi-1/Qua-2/Unde-Quo-2;Ubi-1/Ubi-2/Qua-2;Ubi-1/Qua-1/Qua2; Ubi-1/Qua-2/Unde-Quo-2/Ubi-2; Ubi-1/Unde-Quo-2/Qua-2/Qua-1.

Antes de pasar a ejemplificar la anterior combinatoria, hemos de señalar que la combinatoria de tres expresiones locativas (sin considerar a Ubi-1) es muy rara y forzada, siendo quizás preferible pensar en la pertinencia de oraciones incrustadas; y en muchas ocasiones es posible considerar una lexía compleja formada por el predicado verbal y el complemento Qua-2. Igualmente, hay algunas construcciones donde el elemento pertinente de la expresión Undę-Quo-2 está dado temáticamente en forma de Ubi-1 (aparte los casos en que está dado co(n)textualmente). En cuanto a la jerarquía remática hemos de considerar lo siguiente: el complemento Unde-Quo-2, obligadamente presente con los verbos direccionales -salvo cuando van construídos con Unde-Quo-1-, y que puede estar expreso sintagmática o co(n)textualmente, cumple el papel de actante, siendo su consideración remática informativamente relevante. Cuando aparece en combinación con otro complemento (salvo Ubi-1, que tendrá rango 6), este otro complemento tendrá una función circunstancial, y será informativamente más relevante que la expresión locativa actante. Son estos, quizás, los casos que pueden hacer pensar en un rango remático 1 y 3 según sea la expresión locativa actante o circunstante. Con verhos estativos y localizables resulta problemático distinguir el rango remático de sus elementos, sabemos que es muy informativo, pero todo lo que sea decantarnos por un rango 1 ó 3 según su función actancial o circunstancial es mera hipótesis de momento. Ejemplos:

8. El camino va de Molina a Espinardo.

9. En las procesiones, Juan siempre va en la fila de la izquierda.

10. En las manifestaciones, Juan siempre va por detrás de los socialistas.

11. En Madrid, Juan siempre va por el camino más lento.

12. En la playa, Juan siempre llega a casa muy tarde.

13. En Alicante, Juan llegó a la meta por detrás de los 20 primeros.

14. En Alicante, Juan llegó a la meta detrás del primero.

15. En Alicante, Juan llegó a la meta por un atajo.

16. Juan yenía por la carretera delante de todos.

17. Juan llegó por el atajo por delante de todos.

18. Juan llegó a casa por el atajo delante de todos.

19. Juan llegó a casa por el atajo por delante de todos.

20. En Alicante, Juan llegó a la meta por detrás de los 20 primeros.

21. En Alicante, Juan llegó a la meta detrás del primero.

22. En Alicante, Juan llegó a la meta por un atajo.

23. En el camino de Molina a Murcia, Juan llegó por el atajo delante de todos.

24. En el camino de Molina a Murcia, Juan llegó por el atajo por delante de todos.

25. En Madrid, Juan llegó a la meta por el atajo delante de todos.

26. En Madrid, Juan llegó a la meta por el atajo por delante de todos. 
La primera consideración que nos interesa señalar de todo esto es la enorme complejidad que puede llegar a tener el análisis de estas frases conforme vamos haciendo más y más combinaciones.

Hay algunas construcciones donde resulta problemático delimitar lo temporal y lo espacial; así: 13, 14, 16, 17, 18, 19, 20, 21, 23, 24, 25, 26. Las expresiones Ubi-2 y Qua-1, construcciones con verbos de desplazamiento, parecen resultado de una imbricación entre espacio y tiempo. Estos predicados indican un desplazamiento, por tanto son perfectivos, frente a las expresiones localizadoras que son concretas y que entonces pasan a indicar el orden de ese desplazamiento; pero el orden espacial de desplazamiento viene dado por un orden temporal de desplazamiento, en especial cuando está construído con Unde-Quo-2 y en situaciones fictivas, no de situación presente.

Así pues, podemos concluir la siguiente tendencia con las combinaciones que venimos comentando: especialmente claro en los casos de situación imaginada y cuando también funciona una expresión Unde-Quo-2, estos casos Ubi-2 y Qua-1 sufren una imbricación de contenido de forma que su orden posicional, orden de lugar u orden de desplazamiento, es un producto híbrido espaciotemporal.

Otro aspecto que parece muy interesante mencionar es la vinculación de las expresiones Ubi- 1 con la base de alguna de las expresiones también predicadas. La base es el objeto localizante en tanto que es el elemento conocido y a partir del cual podemos localizar la figura; entonces, es comprensible que en muchas ocasiones este elemento -o su ubicación genérica- venga tematizado como marco de referencia del proceso discursivo señalado.

Creemos importante señalar el proceso de recategorización que pueden sufrir alguno de estos verbos direccionales, de forma que, de significar el desplazamiento pasarían a significar la manera de ese desplazamiento, neutralizando su contenido local direccional en favor de la manera de ese desplazamiento. Es un proceso si se quiere contrario al de los verbos semilocales, y que afecta a la pérdida de la necesidad del complemento UndeQuo-2. Estos casos se producen principalmente con construcciones Qua-2 sin especificación Unde-Quo-2. En estos casos, Qua-2 es actante, pudiéndose llegar a producir una neutralización con los Qua-1 y Ubi-2; ej.: 9, 10, 11, 16, 17 (más claros con uso de ir), 23, 24. Cuando sólo está expresado uno de estos complementos queda neutralizado como Qua2, funcionando actancialmente; si hay más elementos, el que no funcione como Qua-2 será circunstante. En alguno de estos ejemplos es replanteable la cuestión de si se trata de lexías complejas tipo "ir por $X$ ", donde no se predica un desplazamiento, sino la ubicación de la manera de ese desplazamiento.

Un último aspecto que queríamos comentar es la generalización de la propuesta de la imbricación del contenido léxico de determinados elementos locales. Las expresioes Qua-1 y Ubi-2 con verbos de desplazamiento en los que está marcado este desplazamiento, desarrollan, en general, un contenido híbrido entre lo espacial y modal. Ej.: "Salió de su casa por la puerta principal frente a todo el mundo"/"En Madrid, Juan entró en la iglesia por delante de su mujer". Si bien en los ejemplos primeros hablamos de una imbricáción espacio-tiempo fue porque se trataba, generalmente, de carreras, donde la manera, entonces, es el orden. Esto ocurre claramente en situaciones fictivas; en cuanto a las situaciones presentes, por ser lo espacial con lo que nos relacionamos de una manera más directa, puede estar favorecido frente a otras modalidades, pero sigue siendo híbrido. Caso aparte lo constituyen los posibles ejemplos de recategorización o lexicalización modal del desplazamiento.

Así pues, podemos concluir lo siguiente: 
1. Un verbo direccional necesita obligatoriamente -en un plano noemático del lenguaje- un punto de origen y uno de destino (expresión Unde-Quo-2).

1.1. Es muy común que sólo se predique uno de los dos pasos del movimiento; pudiendo ocurrir que no se exprese el otro por: suspensión, localización co(n)textual, el semismo del verbo en cuestión.

1.2. Este complemento direccional desempeña una función actancial y es relevante temáticamente.

2. Los verbos direccionales pueden verse acompañados por un complemento Qua-2, que desempeñará funciones circunstanciales y será remáticamente más relevante que el actante.

2.1. Este complemento Qua-2 puede afectar a la recategorización de determinados esquemas predicactanciales, de forma que, en lugar de indicar un desplazamiento, indique la ubicación de la manera de ese desplazamiento: un camino o vía. En estos casos, en que no se desarrolla un complemento Unde-Quo-2, tiene función actancial.

3. Las expresiones Ubi-2 y Qua-1 con verbos direccionales no expresan localización sino un contenido que podemos recoger bajo la denominación genérica de "modal", aunque en determinadas construcciones (situaciones presentes) puede estar privilegiada la "manera espacial". Desempeñarán un papel circunstancial de un alto valor remático.

4. Las expresiones Ubi-1, vinculadas específicamente con la generalización de determinada base espacial de los complementos locales, son un elemento temático de presentación o marco de referencia, y tienen el valor más bajo en la escala de jerarquía remática de estas unidades.

5. Estos elementos pueden funcionar en combinación sintagmática, pero sólo podrá aparecer un representante de cada forma casual.

C) VERBOS SEMILOCATIVOS: En los verbos semilocativos, tipo volar, conducir, etc., ya dijimos que eran tales porque eran predicádos en cuanto a la manera de ese desplazamiento, no simplemente como direccionales y no simplemente como un modo de acción, siendo identificables estos dos últimos casos por la presencia de un elemento Unde-Quo-2 y por la ausencia de complementos locales. Vamos a tratar conjuntamente su funcionamiento como semilocativos y su recategorización como direccionales, comportando la posibilidad de combinación con las siguientes expresiones locativas: Ubi1, Qua-2, Unde-Quo-2. Las combinaciones que se pueden hacer con estos elementos son todas las que las matemáticas nos permiten: Ubi-1; Qua-2; Unde-Quo-2; Ubi-1/Qua-2; Ubi-1/Unde-Quo-2; Qua-2/Unde-Quo-2; Ubi-1/Qua-2/Unde-Quo-2.

27. En Madrid, Juan conduce por el carril del centro.

28. En la playa, Juan nadaba desde la Galera hasta el Faro.

29. Juan condujo de Madrid a Barcelona por autopista.

30. En la playa, Juan nadaba de un lado a otro por los sitios más profundos.

Al igual que con los verbos locativos direccionales, las expresiones Ubi-1, vinculadas a la base de alguna de las expresiones localizadoras, tienen una función circunstancial en tanto que se limitan a presentar o enmarcar la situación. Son elementos temáticos que ocupan el nivel más bajo en la jerarquía remática del español. Pueden darse tanto con el valor local de los verbos semilocales como con su valor modal.

Con las expresiones Unde-Quo-2 se cumple una función actancial, relevante temáticamente.

En cuanto a las expresiones Qua-2, cuando se dan combinadas con Unde-Quo-2, tienen una función circunstancial, y ocupan el rango más alto de relevancia remática, por 
encima de los Unde-Quo-2. Acogiéndonos a la clasificación de Contreras, podríamos decir que delimitan los rangos 1 y 3 . Sin embargo, y a diferencia de los verbos locativos, cuando estas expresiones aparecen solas (mejor dicho, sin verse acompañadas por Unde-Quo-2) desempeñan una función actancial, de fuerte relevancia remática -igual a la de los UndeQuo-2, pero, no tan alta como cuando funcionan circunstancialmente-. En estos casos ya no se predica un desplazamiento, sino la vía o camino, la ubicación, de la manera de ese desplazamiento: "Juan conduce por el arcén"/"Juan pasea por el bosque". Estos verbos son marcados respecto a los direccionales porque se predica la manera o el modo del desplazamiento (por tierra, por aire, etc.), frente a los direccionales, que, básicamente, se refieren a un contenido exclusivamente local. Se trata, en definitiva, del mismo uso que señalamos de algunos verbos locativos que pueden ser recategorizados como semilocativos, así $i r$, por ejemplo, puede ser predicado en cuanto a la ubicación de la manera del desplazamiento. El verbo ir, cuando no está marcado deícticamente, puede ser predicado como forma o modo de desplazamiento, pero neutro respecto a todas las posibles maneras; es decir, ir funciona en estas ocasiones como archisemema de conducir, volar, etc.; no es por tanto extraño que pueda predicarse actancialmente con Qua-2.

Los verbos locativos direccionales predican un desplazamiento; es por tanto razonable pensar que las únicas funciones actanciales noemáticamente exigibles sean la de agente-objeto y la localización de los puntos de desplazamiento. Sólo circunstancialmente será exigible el camino o vía por donde se da ese desplazamiento, salvo en los casos en los que ya no se predica el desplazamiento en sí, sino la manera de ese desplazamiento ir por- resultando entonces exigible semantemáticamente el complemento Qua-2. Los verbos semilocativos no predican el desplazamiento, sino una forma de desplazamiento, pudiendo entonces predicarse localmente o de otra manera; si se hace localmente ya no se exigen los puntos de desplazamiento, sino la ubicación del desplazamiento, y esa ubicación del desplazamiento es el camino o vía por el que se desarrolla. Ahora bien, al igual que ocurría con el verbo ir, entendido como la neutralización archisemémica de las maneras de desplazamiento, se puede dar el mismo caso, pero a la inversa; es decir, se puede predicar con un verbo semilocativo un desplazamiento -aunque con unas características peculiares-, siendo entonces exigible actancialmente un elemento Unde-Quo-2, y sólo circunstancialmente una expresión Qua-2.

Por tanto, los verbos locativos direccionales tienen una complementación característica que los define, las expresiones Unde-Quo-2, pudiendo recategorizarse el contenido sémico del verbo de forma que sea una expresión Qua-2 la exigible actancialmente, funcionando en el resto de los casos como elemento circunstancial. La complementación local característica de los verbos semilocativos, que los define noemáticamente, es la de las expresiones Qua-2, teniendo igualmente un funcionamiento actancial; pero estos verbos también pueden recategorizarse de forma que necesiten específicamente una expresión Unde-Quo-2, resultando entonces la expresión Qua-2 sólo exigible circunstancialmente; se trata de un funcionamiento similar al característico de los verbos direccionales.

Las expresiones Qua-1 y Ubi-2 tienen un funcionamiento equivalente al dado en los verbos direccionales; es decir, expresan más una manera o modo que un contenido propiamente espacial, a excepción de los casos en que neutralizan sus valores con los de las expresiones Qua-2 ("Juan conduce en la carretera"/"Juan vuela por encima de Madrid").

Así pues, el esquema provisional que resulta de todo lo anteriormente dicho es el siguiente: 
, Verbos localizables $\left[\begin{array}{l}\text { Qua-1, circunstante (Qua-2 se neutralizan con él). } \\ \text { Ubi-2, circunstante. } \\ \text { Ubi-1, circunstante enmarcador (combina con los otros dos). }\end{array}\right.$

Verbos semilocativos $\left[\begin{array}{l}\text { Qua-2, actante (posibilidad de neutralizaciones de Ubi-2 y Qua-1). } \\ \text { Unde-Quo-2, actante (recategorización); Qua-2 combinado con estas } \\ \text { formas circunstante. } \\ \text { Todos se pueden completar con Ubi-1, e incluso expresar sin otros } \\ \text { complementos locales, pero entonces ya no se predica un } \\ \text { complemento local. Circunstante enmarcador. }\end{array}\right.$

Verbos
locativos $\left[\begin{array}{l}\text { Estativos } \\ \text { Direccionales }\left[\begin{array}{l}\text { Ubi-2, actante. } \\ \text { Qua-1, actante. } \\ \text { Ubi-1, circunstante enmarcador. }\end{array}\right. \\ {\left[\begin{array}{l}\text { Unde-Quo-1, actante. } \\ \text { Unde-Quo-2, actante. } \\ \text { Ubi-1, circunstante enmarcador (combina } \\ \text { con todos). } \\ \text { Qua-2, circunstante (salvo recategorizaciones, donde es actante, } \\ \text { pudiendo neutralizarse con Ubi-2 y Qua-1. }\end{array}\right.}\end{array}\right.$

\section{La estructura del movimiento.}

L.Talmy (1975) define la estructura semántica de lo que llama situación de movimiento, como un sistema con cuatro constituyentes: figura, base, camino y movimiento. La figura y la base son el objeto localizado y localizante respectivamente; en cuanto a los otros dos, viene a identificarlos con los locativos espaciales y con la generalización del movimento y la localización.

"The respect in which one object is considered as moving or located to another object is (functions as) the PATH, or P, of the motion situation (a locational 'site' is considered the limiting case of a PATH).

The moving or located state that one object is considered to be in with respect to another object is (functions as) the MOTION, or M, of the motion situation (a located state is considered the limiting case of MOTION). (L.Talmy, 1975: 181-182)

Estas funciones semánticas se definen por sus relaciones recíprocas, y caracterizan así la estructura semántica de la situación de movimiento. Cada constituyente de esta estructura semántica corresponde a una categoría gramatical particular: los constituyentes que especifican la figura y la base son nominales, el constituyente que especifica el camino es preposicional (relacionante, diríamos nosotros), y el constituyente que especifica el movimiento es un verbo. Precisa igualmente que estas categorías pueden admitir realizaciones diferentes. Así, el constituyente preposicional puede darse como preposición, posposición, prefijo o sufijo, lo cual está en consonancia con nuestra visión prototípica de los locativos espaciales (Cifuentes, 1989).

En un trabajo posterior, Talmy (1985), actualiza y universaliza alguna de las 
sugerencias e ideas que ya fueron expuestas en su primer trabajo. Así, a los cuatro constituyentes internos anteriores añadirá uno externo, el de manera o causa.

"This category refers to the qualitatively different kinds of causing events such as can be expressed by an English subordinate from-or by-clause (...). Manner refers to a subsidiary action or state that a Paticnt manifests concurrently with its main action or stalc." (L.Talmy, 1985: 128)

Igualmente señalará el importantísimo hecho de la posibilidad de amalgamar distintas categorías en una sola.

A pesar de que nuestro estudio no pretende ser contrastivo -a diferencia del de Talmy-, asumiremos como imprescindibles la mayoría de las propuestas de éste, pese a que algunos ejemplos que da en español son muy dudosos. Sin embargo, las categorías semánticas y sintácticas que distingue tienen una pertinencia funcional imprescindible para lo que es nuestro objeto de estudio.

Podría ser discutible englobar en una categoría subyacente única los verbos de estado y los de movimiento, en tanto que definen dos estructuras diferentes, pero de lo que no cabe duda es de la necesidad de distinguir elementos actanciales y circunstanciales, cosa que Talmy no hace, y las fundamentales nociones de movimiento sin cambio de lugar, y movimiento con cambio de lugar.

\subsection{La oposición movimiento y desplazamiento.}

Aunque el movimiento se define como un proceso dinámico en oposición al estatismo del estado, no se deduce de ello que el movimiento conduzca a un cambio de lugar, es decir, a un desplazamiento. La conceptualización de un fenómeno extralinguístico como el movimiento determina -en parte, al menos- la forma lingüistica por la que es expresado. La base sobre la que se presenta la significación de una expresión es un dominio cognitivo (Langacker, 1988: 63).

Dervillez-Bastuji (1982: 297-324) distingue entre movimiento del objeto que efectivamente cambia de posición en el espacio en función del tiempo, y modificación del referente, es decir, de las marcas espaciales en función de las cuales es aprehendido el movimiento marcado en el proceso y el cambio de lugar que implica. Al igual que un objeto móvil puede desplazarse en un lugar fijo que le sirve de locativo escénico (Ubi-1), un objeto puede mostrarse inmóvil en otro lugar-objeto sometido a un proceso de movimiento o de desplazamiento.

El movimiento no dirigido es asimilable a un estado: "bailar" o "barrer" es producir un movimiento no orientado, es decir, reducible a un círculo cuya miniaturización da el punto.

"En conséquence, on considérera comme radicalement insuffisante, du point de vue des relatiuns spatiales, l'opposition ordinaire entre Mouvement et non-Mouvement, qui confond le mode d'Action du procès avec son incidence Spatiale (...). Dans l'opposition Mouvement/Repos, l'opposition des catégorics sémantiques (-Statique) intéresse la manière dont se déroule le procès ou l'étal. Dans l'opposition Déplacement/Localisation, les mêmes catégories sémantiques jouent sur le rapport de l'opérateur de prédication, qui est le plus souvent un verbe, avec le SN de lieu: il s'agit alors de lincidence spatiale du verbe, ou facteur (I.S.)." (Dervillez-Bastuji, 1982: 306)

El desplazamiento puede ser señalado tanto por un verbo tradicionalmente transitivo (en combinación con lo que se ha llamado un complemento directo) como por uno 
intransitivo. Si es intransitivo no puede aplicarse más que al sujeto como figura; si es transitivo, el desplazamiento puede referirse tanto al sujeto como al objeto, o a los dos conjuntamente; un verbo intransitivo puede incluso especificar un movimiento del objeto sin que se acompañe de desplazamiento. En estos casos tendremos un problema de ambigüedad. Estos aspectos son señalados por Dervillez-Bastuji (1982: 301-307) para el francés, pero, como tendremos oportunidad de demostrar, también son aplcables al español.

La noción de orientación se analiza, pues, como un cierto estado resultativo de un movimiento o de un desplazamiento, real o virtual. Orientar un objeto es disponerlo en una dirección determinada.

Dervillez-Bastuji esquematiza el juego del movimiento y reposo, de la localización, del desplazamiento y la orientación, en los dos esquemas siguientes, tratando uno sobre el modo de acción o de estado del verbo (M.A.) y el otro sobre la relación espacial implicada (I.S.):

\begin{tabular}{|c|c|c|}
\hline \multirow{3}{*}{$\begin{array}{l}\text { +Statique } \\
\text {-Mouvement } \\
\text { (=Etat) }\end{array}$} & \multicolumn{2}{|c|}{ + Dynamique } \\
\hline & \multicolumn{2}{|c|}{ + Mouvement } \\
\hline & Libre & Orienté \\
\hline $\begin{array}{l}\text { LOCA } \\
\text { Loc Z }\end{array}$ & $\begin{array}{l}\text { LISATION } \\
=\text { Loc }_{0}\end{array}$ & $\begin{array}{l}\text { DEPLACEMENT } \\
\text { Loc } Z=\text { Loc }_{0}\end{array}$ \\
\hline
\end{tabular}

Etat/Procès

\begin{tabular}{|c|c|c|}
\hline R. Spatiale Procès & + Statique & + Dynamique \\
\hline $\begin{array}{r}\text { Loc } \mathrm{Z}=\text { Loc }_{1)} \\
\text { (Ponctuel) }\end{array}$ & Etat & Movt. libre \\
\hline $\begin{aligned} \text { Loc } \neq & \text { Loc }_{i} \\
& \text { (Vectoriel) }\end{aligned}$ & Orientation & Déplacement \\
\hline
\end{tabular}

Incidence spatiale (Dervillez-Bastuji, 1982: 307)

Todo desplazamiento puede ser reducible a un vector geométrico del que se puede definir la magnitud, la dirección y el sentido. La magnitud del vector $\mathrm{AB}$ es la distancia recorrida entre $A$ y $B$; el sentido del vector define una orientación secundaria según sea considerado positivamente como yendo de $A$ hacia $B$, o negativamente como yendo de $B$ hacia A. La categoría semántica del desplazamiento articula, pues, una oposición entre el punto de partida y el de llegada, resultante de la doble orientación vectorial según la dirección y el sentido.

La oposición movimiento/desplazamiento no impide su representación común en un vector, que sería la figura de todo proceso y de todo cambio; la diferencia estribaría en que mientras en el desplazamiento los límites de salida y llegada recortan también lugares, con el movimiento la referencia espacial permanece sin cambio. Es muy importante no confundir, señala Dervillez-Bastuji, la localización resultativa de un desplazamiento con la localización escénica que se aplica a la totalidad de un desplazamiento o de un movimiento, es decir, Ubi-1 con Ubi-2, lo cual también nos explica por qué los verbos locativos direccionales sólo pueden combinarse con Ubi-1 y no con Ubi-2, ya que estos últimos tomaban otros valores que no eran los locales. 
Así pues, analizando las causas y los efectos de la confusión clásica entre movimiento y desplazamiento, hemos mostrado con Dervillez-Bastuji que el movmiento no especifica más que la manera en que se desarrolla el proceso, o factor (M.A.), en oposición a la incidencia espacial, o factor (I.S.), que define la relación entre el proceso y el lugar de referencia. Todo movimiento no orientado equivale a un estado, que se manifiesta como reposo o como agitación; a este reposo o movimiento libre se opone el desplazamiento como trayecto orientado definido por su dirección, y, secundariamente, por su sentido, al menos para el origen.

\subsection{Modo de acción.}

El modo de acción, allegable en cierta forma al manner de Talmy, es un rasgo fundamental para la delimitación de los verbos semilocativos. Restringiéndonos simplemente al posible corpus de los verbos locativos y semilocativos, el rasgo [ + modo de acción] estará más o menos presente en unos y otros, en tanto que todo verbo indica un cierto desarrollo o proceso. Sin embargo, estará funcionalmente presente en aquellos verbos que denominamos semilocativos y en los procesos señalados de recategorización de ciertos verbos direccionales. Con estos verbos es pertinente el rasgo [+ modo de acción] junto con el rasgo [+espacialización] propio de la incidencia espacial y que es el que caracteriza la necesidad específica o semantemática de la localización espacial. Sintácticosemánticamente este rasgo hace entrar en funcionamiento la necesidad específica del complemento Qua-2.

Los verbos semilocativos funcionaban como tales cuando, además de predicar el modo de acción, señalaban una incidencia espacial. Si to que se predica es el modo de acción de un desplazamiento y no el desplazamiento, entonces la incidencia espacial de la predicación es relativa al camino o vía del desplazamiento, lo cual es expresado por un locativo con forma casual Qua-2. Con volar o conducir no sólo se predica un desplazamiento, sino la manera de ese desplazamiento, su modo de acción.

Llamamos recategorización direccional al proceso que sufrían estos predicados semilocativos por el cual el componente direccional (que es el que especifica un origen o punto de partida y una meta o punto de llegada y que, en su uso característico, no es que no venga dado, sino que viene neutralizado, pero sigue considerándose, ya que es él el que confiere el rasgo de desplazamiento) viene marcado específicamente, pasando a necesitar entonces específicamente un complemento Unde-Quo-2 y tan sólo genéricamente una forma Qua-2. Por tanto, cuando el rasgo direccional viene marcado, el rasgo modo de acción pasa a tener una función secundaria, reflejada en el papel circunstancial de los Qua-2 -como ocurre con los locales direccionales-.

Igualmente, había algunos verbos direccionales que podían ser neutralizados en cuanto a su rasgo direccional, y predicados en cuanto a su modo de acción, así ir, que era entendido como archisemema del rasgo modo de acción y acción globalizadora del conjunto de maneras de desplazamiento. En estos casos, la recategorización a que hacíamos alusión consiste en la neutralización del rasgo direccional y el funcionamiento del rasgo modo de acción, produciéndose entonces una necesidad específica de Qua-2, que tan sólo era de coherencia clasemática en su predicación como direccionales, teniendo una función circunstancial y secundaria.

El rasgo modo de acción, por tanto, según venga acompañado del rasgo direccional o no, puede expresar -a través de un complemento Qua-2- una función actancial o circunstancial, pudiendo distinguir verbos locativos direccionales de semilocativos, pero ello 
era siempre y cuando estuviera expreso el rasgo de espacialización, que es el que hace necesaria la presencia de un complemento local. Ya comentamos que los verbos semilocativos pueden ser predicados también sin el rasgo [+incidencia espacial], predicándose simplemente como modo de acción; en este caso no se construyen con expresiones localizadoras (sintagmática o co(n)textualmente), salvo la posibilidad que tiene de aparecer un enmarcador Ubi-1. Algunos verbos direccionales $(i r$, subir,...) tienen esta misma posibilidad de funcionamiento, pero siempre y cuando sea factible el encontrar una relación hiponímica con un conjunto de verbos semilocativos. Ya comentamos que "ir" podía funcionar como semilocativo y funcionar igualmente de forma no local ("Ahora Juan va muy bien"), ya que constituía un archisemema de todas las maneras de desplazamiento. Cuando se puede encontrar una relación hiponímica entre distintos verbos semilocativos y determinado verbo locativo direccional, este puede recategorizarse como semilocativo, haciendo pertinente funcionalmente entonces el rasgo [+ modo de acción] al neutralizar el rasgo [+ direccional], e incluso puede llegar a predicarse basándose simplemente en este rasgo [+ modo de acción] en ausencia del rasgo [+ espacialización]. Podemos plantear que estos casos de recategorización se producen por identificación del hiperónimo con sus hipónimos.

La conclusión es que los verbos semilocativos pueden recategorizarse como locativos direccionales al hacer entrar en funcionamiento el rasgo [+direccional], siendo entonces el rasgo [+ modo de acción] secundario; y pueden también recategorizarse en determinados usos como no locativos al perder el rasgo [+espacialización] y sólo funcionar el rasgo [+modo de acción]. Los verbos direccionales pueden recategorizarse como semilocativos al neutralizar el rasgo [+direccional] y privilegiar el rasgo [+ modo de acción]; e incluso pueden llegar a recategorizarse como no locativos perdiendo el rasgo [+incidencia espacial], pero esto último es posible si el verbo direccional se halla en relaciones hiperonímicas con verbos semilocativos como hipónimos, pudiendo darse este empleo por analogía al que sufrían los semilocativos.

\subsection{Verbos transitivos e intransitivos.}

Dervillez-Bastuji (1982: 228-229) señala que ciertos verbos que especifican una localización se construyen con un objeto y otros con un sintagma preposicional de lugar (si su función es actancial, determinan la llamada transitividad directa e indirecta 0 preposicional); la arbitrariedad llegará a ser tal, que ciertos verbos admiten la doble construcción preposicional y no preposicional sin modificación semántica apreciable (una cierta bivalencia funcional). Así, ciertos verbos de desplazamiento se construirán tanto transitivamente con el objeto semántico afectado por el desplazamiento, como intransitivamente con el camino por el cual se efectúa el desplazamiento: "Juan sube las escaleras" /"Juan sube por las escaleras". Sin embargo, empezaremos ocupándonos del rasgo [+ causalidad], que deteminará la tradicional transitividad o intransitividad de ciertas construcciones locales; y digo tradicional, ya que resulta manifiesta la función actancial de ciertas construcciones locativas: las que actualizan el rasgo [+espacialización].

El aspecto que entendemos como rasgo [+ causalidad] determina la aparición de un complemento directo como figura de localización diferenciado de un sujeto agente o causa de la localización. Es evidente que las construcciones ergativas o causativas están relacionadas con el fenómeno de la transitividad en general, sin embargo su esquema es parcial pues sólo afecta a determinados esquemas y no es aplicable a todos los casos posibles. En lo que a la localización se refiere, disocian la figura del agente-causa sujeto 
de la acción que hasta ahora solía coincidir. Igualmente tampoco nos ocuparemos de la causalidad en tanto vinculada a la eferencia -como la finalidad a la aferencia-.

En todos los casos que hasta ahora veníamos considerando, la figura u objeto localizado desempañaba la función sintáctica de sujeto, siendo esta figura tanto causa como objeto del movimiento, es decir, es la localización (estativa o directiva) del propio agente la que se predica, es el propio sujeto, en tanto agente, el que es localizado (venir, estar, etc.). El rasgo [+ causa] es pertinente en aquellos casos en los que se diferencia objeto y agente de la localización, funcionando el agente como causa de la localización, y pudiendo este mismo agente-causa estar inclúdo en la predicación de la localización o no.

En casos como "Juan no trajo el coche"/"Juan puso el sombrero en la percha", la forma locativa -explícita o dada contextualmente- manifiesta la localización de una figura que no es agente: 'coche' y 'sombrero', y que viene expresada sintácticamente como objeto directo. El sujeto es la causa de la localización de la figura, y puede estar incluído en la localización ('traer') o no ('meter' vs. 'meterse'). Estas formas locativas -actanciales con el tipo de construcciones expuestas han obligado la aceptación por parte de Alarcos (Martínez García, 1986: 4) de que suplemento e implemento pueden coocurrir, cosa que ya había puesto de manifiesto Bosque (1983) y Martínez García (1986: 188-189). Alarcos denomina a este tipo de expresiones "suplementos indirectos", puesto que no determinan inmediatamente al núcleo sino a través del imprescindible implemento.

Estas últimas consideraciones nos pueden ayudar a entender las primeras estructuras transitivas señaladas: "subir" y sus hipónimos en esquemas locativos, por ejemplo, pueden construir una localización con sintagma nominal o con sintagma preposicional, pero "subir" también puede actualizar el rasgo [ + causa] -a diferencia de los anteriores ejemplos, donde este rasgo era intrínsecamente característico-; "Juan sube un perro por las escaleras", en este caso el agente también está incluído en la localización del objeto figura. $\mathrm{Si}$ conmutamos el sintagma preposicional locativo por el que era su sintagma nominal, comprobamos la no aceptabilidad de la expresión ( ${ }^{*}$ Juan sube un perro las escaleras). Esto nos hace pensar en dos posibles soluciones: o bien se consideran estas expresiones como sintagmas estereotipados donde la preposición se ve reducida a un uso demarcativo facultativo, o bien se trata de dar una explicación a partir de los procesos de recategorización expuestos en el apartado anterior (y, en una posición ecléctica, quizás esta segunda posibilidad da razón de la primera).

El verbo "subir", por ejemplo, es entendido noemáticamente como direccional aunque tiene una gran frecuencia de empleos recategorizado-. En una construcción locativa Qua-2 como la anterior se ve recategorizado como semilocativo mediante la neutralización del rasgo [+direccional] y la funcionalidad del rasgo [+modo de acción]. Pero recordemos que los verbos semilocativos -y los direccionales así recategorizadospueden sufrir una recategorización que supone la pérdida de su empleo local mediante la ausencia funcional del rasgo [+espacialización], teniendo un funcionamiento simple y llanamente como "modo de acción". Entendemos que este es el efecto producido en estas construcciones de "subir + sintagma nominal", donde se predica un modo de acción sin incidencia espacial, es decir, espaciado pero no espacializado. Es una 'ligera' diferencia semántica entre una y otra construcción pero que actualiza unas 'interesantes' diferencias sintácticas. Se trata de un proceso similar al de "saltar dos metros" o "correr dos kilómetros", donde nos encontramos con verbos semilocativos recategorizados mediante la pérdida distintiva del rasgo [+espacialización], funcionando entonces simplemente en cuanto "modo de acción". Esta explicación nos sirve igualmente para entender el verbo estar, que, con el rasgo [+ espacial], se construye con complementos locativos, y, ausente 
ese rasgo, se predica simplemente en cuanto modo de acción, mejor dicho, en cuanto manera o modo de un estado, es decir, se predica una cualidad, de ahí sus usos atributivos. Moreno Cabrera (1987: 33-45) al señalar la vinculación entre localización y atribución como pertenecientes a la misma función de 'adscripción', comenta la posibilidad de entender la localización como un caso especial de atribución: o bien atribuímos a una entidad la propiedad de estar en algún lugar, o bien le atribuimos una cualidad; es decir, es el rasgo [+incidencia espacial] el que posibilita la distinta predicación.

\subsubsection{Expresiones directas e indirectas.}

Vernay (1974: 183-185) señalaba el hecho de que ciertas construcciones Qua-2 pueden ser expresadas verbalmente. Dervillez-Bastuji (1982: 227-228) recoge igualmente este fenómeno y comenta que ciertos verbos, producidos por derivación denominativa, incorporan en su semantema.o núcleo sémico una información espacial que en otras construcciones es especificada por una expresión locativa. Estos verbos tienen la propiedad sintáctica de construir como implemento el suplemento locativo: "Juan fue a través del bosque"/"Juan atravesó el bosque"; "la casa está al borde de la carretera"/"la casa bordea la carretera".

Estas construcciones también se dan con verbos que tienen actualizado el rasgo [+ causa], especialmente con poner; en estos casos lo que ocurre es que la figura, en función de implemento, es incorporada al contenido sémico del verbo, y el caso locativo es expresado en forma de implemento: "Juan puso sal en la comida"/"Juan sazonó la comida".

L.Talmy, en un estudio sobre muchas y muy distintas lenguas (1985: 102-121), señala la necesidad de reconocer un interesante constituyente superficial presente en muchas si no en todas las lenguas. Es lo que denomina satélite.

\footnotetext{
"..., satellites are certain immediate constituents of a verb root other than inflections, auxiliaries, or nominal arguments." (Talmy, 1985: 102)
}

Los satélites se relacionan con el verbo como modificadores a un núcleo; un verbo con sus satélites forma lo que denomina "complejo verbal", y es este constituyente asì formado el que se relaciona con los otros constituyentes o funciones de la oración. En algunos casos, estos elementos que actúan como satélites pertenecen a tradicionales categorías gramaticales como preposiciones y adverbios. Los satélites son fácilmente ejemplificables en inglés: "come right/back/down/out form up in there!", dicho, por ejemplo, por un padre a su hijo en una casa en un árbol.

El término tradicional aplicado a estos elementos era el de "partícula verbal" (Fraser, 1976), pero Talmy introdụce el término "satélite" para señalar la relación entre tales partículas y formas comparables en otras lenguas. Así, dentro de las lenguas indoeuropeas, tales formas incluyen los prefijos separables e inseparables del alemán, y los prefijos verbales del latín (y el conjunto de las lenguas románicas, añadimos nosotros) y el ruso. Otro tipo de satélite es el segundo elemento de un compuesto verbal en chino, llamado por algunos "complemento resultativo". Otro ejemplo es el llamado por Matisoff (1973) "verbo versátil", una palabra no nuclear en extensas secuencias verbales típicas de las lenguas tibetanas. Un último ejemplo son los afijos no flexionales de la raíz verbal en el verbo polisintético atsugewi.

Talmy señalará una serie de componentes semánticos que son expresados por el 
satélite: 1) el locativo. Talmy comenta que, en inglés, este tipo de satélites debe ser distinguido de las preposiciones, por lo que señalamos en el punto anterior de que muchas veces converge su categoría gramatical; sin embargo, en la mayoría de las lenguas indoeuropeas esta confusión no se da, ya que las dos formas tienen distintas características gramaticales; así, en latín, griego clásico y ruso, el satélite es un término prefijado al verbo mientras que la preposición acompaña al nombre y gobierna su caso. El inglés es quizás la única lengua indoeuropea en la que la posición del satélite y de la preposición están conjuntas en una posición; de todas formas pueden ser diferenciados mediante la elisión de la función actancial con preposición, y, en aquellos casos en que la forma de la preposición y del satélite confluyen, tienen sentidos diferentes. Talmy señala que este mismo tipo de satélites -de los que expone un exhaustivo listado (1985: 106)- también se producen en chino (mandarín); las únicas diferencias existentes entre unos satélites y otros son debidas a su ordenación sintáctica, pero no a sus componentes semánticos.

2) Locativo + base. Un modelo distinto del anterior lo constituyen aquellos satélites que expresan tanto el particular locativo como el tipo de objeto localizante. Los satélites de este tipo son comunes en la mayoría de las lenguas amerindias, así en atsugewi (Talmy, 1985: 107-109). Dos son, sin embargo, los casos que se pueden encontrar en inglés: "she drove home (to her cottage in the suburbs)"/"the gate swung shut (across the entryway)".

3) Paciente: (Figura/Base). Otro satélite es el que indica el paciente de un acontecimiento que está siendo referido. Estos satélites son muy comunes en la mayoría de los sistemas de las lenguas amerindias, e incluyen una forma afijal del satélite dentro del verbo polisintético. El caddo es un ejemplo en este punto, dando el satélite, comúnmente, una identificación más genérica del paciente (Talmy, 1985: 109-110).

4) Manera. Un satélite poco común es el que expresa manera. Un sistema de tales satélites se da en Nez Perce, lengua polisintética de Norteamérica, donde un prefijo añadido a la ráz especifica la particular manera en que el movimiento es realizado (Talmy, 1985: 110-111).

5) Causa. Este tipo de satélites equivalen a una cláusula subordinada expresando causación. La mayor elaboración de estos satélites se da en las lenguas hokan del norte de California (Talmy, 1985: 111-113).

6) Otras lenguas también pueden expresar satélites con un contenido semántico referido al aspecto y valencia combinatoria.

Volviendo al caso del español podemos entender las dos estructuras posibles señaladas por Dervillez-Bastuji (1982) de la siguiente manera: en casos como "Juan no puso sal en la comida"/"Juan no sazonó la comida", donde el verbo locativo está marcado con el rasgo [+ causa], el verbo formado a partir de la figura carece del rasgo [+espacialización], y simplemente se predica una manera o modo de acción pero no una espacialización.

En casos como "Juan fue a través del monte"/"Juan atravesó el monte", donde tenemos un verbo con el rasgo [ + incidencia espacial] pero sin el componente [+ causa] y. con el no funcionamiento del rasgo [+dirección] es posible la gramaticalización y lexicalización del verbo y marca casual, en similitud con los complejos verbales señalados por Talmy -en los que el satélite indicaba el locativo-, con la particularidad de que en inglés, por ejemplo, esta gramaticalizada la expresión pero no lexicalizada, cosa que sí ocurre en español (y, en general, en las lenguas románicas, ya que este era un proceso común en latín, donde las gramáticas latinas señalan que algunos verbos intransitivos indicando movimiento se convierten en transitivos al hacerse compuestos con una preposición, así: "circumeo castra"/"eo circum castra"; "percurro locum"/"curro per locum"; "transeo flumen"/"eo trans flumen"). Las construcciones siempre vienen dadas a partir de 
verbos de amplia extensión, como "ir" construído actancialmente con Qua-2, o con "estar" predicado con Ubi-2. En el primer caso se trata de un verbo de desplazamiento, en el segundo de uno estativo con sujeto no animado.

Cano Aguilar (1981: 92-95) habla en estos casos de conversión del complemento de lugar en objeto directo, y recuerda la idea de Fillmore (1968) de que estos objetos directos superficiales responden a un caso locativo en la estructura semántica subyacente; lo cual está en consonancia con la idea de Lakoff (1971) y McCawley (1975) de que la mayoría de las preposiciones se originan como.parte de verbos: se trata de categorías derivadas, no básicas. No podemos estar de acuerdo con esta última idea aplicada al campo de la localización espacial, aun referida exclusivamente al terreno de las preposiciones en tanto satélites, pues el esquema local necesita un elemento relacionante. Que este elemento relacionante se exprese como satélite sintético o anaítico o como preposición es otro problema. Es el tipo de locativo, en tanto marca casual, el que es generado en las estructuras discursivas pero su función relacionante como espacializador está prevista en el esquema conceptual.

Noemáticamente es posible entender estas construcciones bajo el mismo esquema general de la localización: figura-verbo-locativo-base, con la particularidad de que el locativo se encuentra lexicalizado en el componente verbal (Cifuentes Honrubia, 1989) ${ }^{\text {. }}$. Caracterizaremos este tipo de verbos con el rasgo [+ satélite], indicando con ello que el locativo se encuentra incorporado al esquema léxico del verbo en cuestión, desarrollado a partir del locativo. Noemáticamente no hay razón alguna para separar estos verbos del esquema general de verbo (de desplazamieno o estativo) que localiza una figura mediante una base a través de un locativo, desempeñando la expresión localizadora una función actancial. Es sólo manifestativamente, es decir, en las estructuras discursivas (GreimasCourtés, 1982), donde es posible dotar a estos verbós de unas características peculiares, y ello es debido al rasgo [+satélite], es decir, a que se ha producido la lexicalización de algo tan frecuente en las lenguas como es el satélite con contenido locativo. Esto acarrea que el actante local esté expresado -en español- aparentemente sin marca casual locativa alguna, cuando lo que ocurre es que esta marca casual se ha gramaticalizado con el verbo (complejo verbal: raíz verbal + satélite) y se ha iexicalizado en una sola forma. Esta gramaticalización y lexicalización es producto de un desarrollo gramatical (Coseriu, 1981), es decir, de la tradicional derivación.

La combinatoria sintáctico-semántica de estos verbos con el rasgo [+ satélite] es la siguiente: si está formado a partir de una base verbal estativa es evidente que no podrá combinarse con Ubi-2 con funciones actanciales, ya que es este mismo elemento el que está dado manifestativamente como satélite e implemento. Se podrá combinar con Ubi-1 en función de circunstante enmarcador y con rango remático 6, y con Qua-1, circunstante con rango remático 1, teniendo rango 3 el implemento; igualmente podrá combinarse con Ubi-2 en función circunstancial y rango remático 1 . Al estar basados en verbos de

s Langacker (1988: 63-67) diferenciará ejemplos como "atravesar" e "ir a través de" no en el contenido conceptual de las expresiones, sino, sobre todo, en la forma de acceso a ese contenido; así, la primera expresión se caracteriza por una observación en secuencias (cl acceso a los estados que constituyen el acontecimiento se hace en secuencias, y la conceptualización de cada estado no es más que momentánéa) y la segunda por una observación global (se trata de concebir el acontecimiento de forma más general, sca micntras se obscrva o sea durante una reproyección mental; el acceso a los diferentes estados que lo constituyen se efectúa también en secuencias, pero, una vez actualizado, la conceptualización que corrsponde a un estado dado permanece activa durante todo el proceso de conceptualización); aunque se refieran al mismo tipo de estados y lengan el mismo contenido conceptual, difieren en la manera en que este contenido es conceptualizado en io concerniente al tipo de actualización en el tiempo de la conceptualización. 
desplazamiento, están categorizados como semilocativos, ya que la marca casual lexicalizada y la base expresa en implemento funcionan como Qua-2 actancialmente. Pueden combinarse localmente con Ubi-1, en función de circunstante enmarcador y rango remático 6, y con Unde-Quo-2 en función de circunstante y rango remático 1 , tenjendo el implemento -resultante del Qua-2- rango 3; también pueden combinarse con Qua-2 en función de circunstante y rango remático 1 .

31. En Benidorm, la casa de Juan bordea la costa (en la playa de Levante) (por un sitio maravilloso).

32. En Alemania, Juan atravesó la Selva Negra (de punta a punta) (por un camino vecinal) (sin parar a descansar).

Como se desprende de los ejemplos, hay unas pequeñas diferencias combinatorias con los verbos semilocativos y estativos sobre los que están formados, ya que pueden combinarse con todos los elementos con los que puede combinarse un verbo estativo o semilocal, pero siempre en funciones circunstanciales.

Estos últimos ejemplos nos hacen replantear ciertas construcciones semilocativas como "Juan fue a través de la Selva Negra por un camino vecinal", que parecen contradecir nuestro esquema propuesto. Somos de la opinión de que en estos casos se trata de formas analíticas del complejo verbal (verbo + satélite) -como ocurre en inglés, frente a las formas sintéticas ('atravesar'). Es decir entendemos en estos casos una lexía compleja con el rasgo [+espacial] y con el mismo funcionamiento que los verbos anteriormente descritos, es decir, la base actancial Qua-2 va expresa en forma de implemento, sin marca casual; y la expresión locativa Qua-2 con marca casual desempeña funciones de circunstante. La única manera que se nos ocurre de reconocer este tipo de complejo verbal frente a los casos en que el predicado no está formado con satélite, es la posibilidad de funcionamiento con dos complementos Qua-2 -actante y circunstante-

Estos planteamientos pueden llegar incluso a posibilitar una reconsideración de la noción de suplemento (Martínez García, 1986), ya que la "no sustituibilidad" de la preposición del suplemento se asemeja de nuevo a una tendencia analítica del complejo verbal, en paralelo a la llamada por Galichet (1950: 46-51) "preposición aglutinada". Es decir, las marcas de los suplementos tradicionales serían satélites (de valencia), y la preposición estaría generada en la estructura discursiva. Sin embargo, como muy bien señala Martínez García (1986: 83-84), la preposición del suplemento español tiene un peculiar funcionamiento, derivado de la estrecha unión de la preposición con el sintagma nominal, a diferencia del satélite inglés, por ejemplo, lo cual parece negar la posibilidad planteada.

Cano Aguilar (1981: 362). señala que la alternancia en las construcciones transitivas directas e indirectas implica una diferencia de sentido en el semismo del verbo, y es gracias a la neutralización del rasgo [ + espacialización] como distinguimos las dos posibles estructuras, directa e indirecta de "subir". Los procesos diacrónicos de "subir" pueden ayudarnos a entender su funcionamiento actual en la doble estructura, pues "subir" es compuesto de $s u b+e o$; es decir, se trata de un auténtico complejo verbal en el que el satélite está prefijado, siendo su significado (por lo que nos interesa ahora) "subir, ir de abajo arriba"; es decir, en un principio tenía vigente el rasgo [+satélite], pero con la historia de la palabra éste ha ido perdiendo su noción de complejo verbal y el prefijo 'sub' su valor espacial (sólo reconocible para los especialistas, no para los hablantes), de tal forma que ya no es reconocible su significado espacial, necesitando un locativo para manifestarlo. Otro problema es que el término direccional esté dado contextualmente. De 
forma similar podemos entender que "atravesar/ir a través de", se diferencian en que la balanza de los rasgos [+modo de acción] y [+espacialización] es desigual e inversa, predominando, por ejemplo, más el componente [+ modo de acción] en la forma sintética. L. Lipka (1976) sugiere que una forma léxica compleja debe ser considerada como producto de un proceso de topicalización, entendido como la selección, en la manifestación del lexema complejo, de un foco y un tema o tópico. El tema será el sufijo y foco la base. De ahí que en nuestros ejemplos, al focalizar sobre el verbo en detrimento del contenido espacial del sufijo, se considera como semánticamente prominente su modo de acción.

Así pues, dentro del tipo de locativos lexicalizados al lexema verbal, podemos hacer distintas subclasificaciones atendiendo a una graduabilidad: el rasgo [+ espacialización] estará representado en orden decreciente en las construcciones siguientes: verbo + satélite (complejo verbal, tipo "ir a través de" con otra forma casual Qua-2)/ locativo + base verbal (es el tipo de composición llamada por Coseriu (1978) prolexemática, como "sobrevolar"/ desarrollo a partir de una marca casual locativa ("atravesar")/ desarrollo a partir de un sustantivo ("cruzar"). En este último caso el rasgo [+espacialización] será menos representativo que en los anteriores.

A este respecto, conviene considerar el fundamental trabajo de A.Vera (1987) sobre los procesos de formación de palabras mediante afijos no apreciativos. Vera entiende los procesos de sufijación como lexicalización o manifestación sintética de posibles conceptos también expresables analíticamente. Es decir, las relaciones entre los constituyentes de los sintagmas sufijados son semejantes a las que afectan al mismo tipo de contenidos cuando éstos no son expresados a través de fórmulas sufijadas, sino de manera analítica: "enmarcar/colocar en un marco".

\footnotetext{
"Hemos caracterizado formalmente los procesos de sufijación como procedimientos de condensación de conceptos elementales en conceptos complejos; como un mecanismo de "incorporación" cuya función es la de aglutinar dos conceptos alómicos en una única unidad conceptual cuyos constituyentes establecen entre sí una relación de determinación-identificación, en el sentido que el término posee en E.Coseriu; es decir, una determinación que no procede reduciendo progresivamente la extensión lógica del núcleo determinado, sino designando primaria e instantáncamente los "denotata" del sintagma nombrador." (A.Vera, 1987: 161)
}

El trabajo del Prof. Vera fundamenta el aspecto que venimos comentando en el sentido de que, noemáticamente, es posible entender, en la estructura de la localización o movimiento, la manifestación de ciertos complejos verbales en los que se encuentra amalgamado tanto el proceso verbal como otros constituyentes de la localización. La gramaticalización y lexicalización del satélite en el verbo no sólo puede ser expresada mediante prefijación y desarrollo verbal -como "enmarcar"-. Así, "cruzar" o "enmarcar" nos muestran la lexicalización de la expresión locativa y el proceso verbal (aunque con distinta pervivencia de la marca casual), pero en "atravesar" la lexicalización es del proceso verbal y la marca casual, y ello mediante un desarrollo a partir del locativo, y en "sobrevolar" se trata de la misma lexicalización (proceso verbal/marca casual) pero expresada mediante un prefijo añadido al verbo. Igualmente podemos encontrarnos con ciertos casos en los que el complejo verbal manifiesta analíticamente la gramaticalización del proceso verbal, así determinados usos de "ir a través de".

Por tanto, seguimos manteniendo nuestro esquema de la localización en una perspectiva noemática del lenguaje, pero con la particularidad de que manifestativamente la localización de una base mediante un elemento espacializador puede sufrir diversas amalgamas verbales, funcionando estos satélites analítica o sintéticamente, y estos últimos manifestando explícitamente la marca casual en forma de prefijo o dada contextualmente 
mediante una convencionalización.

\subsection{Amalgamas verbales.}

Talmy (1985: 61-102) expone distintas lexicalizaciones que afectan al verbo en tanto amalgamas de rasgos señalados en su esquema quíntuple de localización:

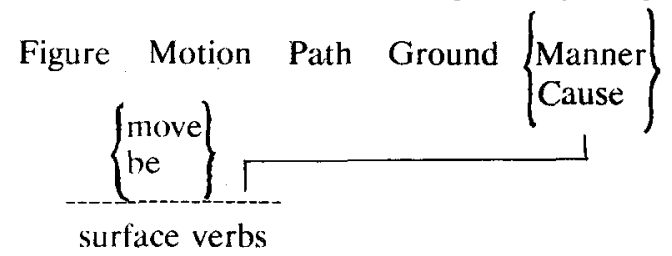

Estos son los rasgos aislados noemáticamente, pero pueden ser expresados manifestativamente en forma de amalgama verbal. Según Rojo (1983: 87 y ss.), las funciones semánticas pertenecen a la forma del significado siempre que lo que encontremos en el significante nos autorice para ello, y los elementos que hay en la sustancia del significado (allegable a ese plano noemático de una lengua determinada del que hemos hablado en ocasiones anteriores) son del mismo tipo; se diferenciarán en que en la sustancia del contenido tienen que estar todas las funciones semánticas, mientras que en la forma del contenido podemos considerar únicamente aquellas que tienen un correlato en el plano significante. De igual forma, la primacía de los esquemas implica que la adscripción o no de una función semántica a la forma de contenido de una lengua no es algo absoluto, pues puede estar perfectamente diferenciada en un cierto esquema semántico y aparecer fundida o 'amalgamada' con otra u otras en esquemas semánticos distintos. De lo que se trata, en definitiva, es de ver que la sustancia está conformada semióticamente (frente a la 'materia', Rojo, 1983: 15 y ss.), de ahí que la sustancia dependa de la forma de que es proyección, lo cual concuerda con el carácter "impositivo" de los marcos (frames) de Fillmore $(1985 ; 1986)$ frente a la pretendida independencia de esquema y guiones (schemas y scripts); y es en este sentido de 'marco', es decir, como un tipo de modelo cognitivo idealizado (Lakoff, 1987), con posibilidad de organizar distintos "espacios mentales", que debemos entender todas nuestras palabras referidas a esquemas y planos noemáticos de la lengua.

Las amalgamas que Talmy señala y que pueden ser aplicadas al español son las siguients (a diferencia de Talmy, nosotros sólo nos referiremos a los verbos con el sema [+espacialización]:

A) Motion + Manner/Cause: Dentro del primer tipo, Talmy hace una distınción según se trate de verbos estativos o direccionales. En cuanto a los estativos, el verbo español posibilita una gramaticalización y lexicalización de la manera (colgar, pender, acostar); sin embargo, frente a verbos ingleses y alemanes, por ejemplo, el español debe acudir a complejos verbales analíticos como "estar de pie", "poner de pie" -según el verbo tenga o no el rasgo [+ causa]-, o mediante un participio o gerundio con la forma verbal respectiva. No es que no funcionen verbos semilocativos estativos, como parece haberse desprendido de nuestro análisis, sino que debido a la frecuencia de uso estos contenidos son expresadaos, generalmente, mediante complejos verbales. Diferenciaremos este tipo de verbos por el rasgo [+ modo de acción], y sabiendo -como en los de desplazamiento-, que pueden no actualizar el rasgo [+espacialización]. De forma similar a como hicimos 
con los direccionales, usaremos el rasgo 'manera' o 'modo de acción' con aquellos que no especifican el tipo de situación, pero sabiendo que se pueden categorizar como semiestativos en determinados usos, lo cual podemos formular de la siguiente manera: cuando el rasgo [+modo de acción] se encuentre actualizado con el rasgo [+ espacialización] recibirá tal nombre, pero si no actualizan el rasgo [+ I.S.], hablaremos del rasgo [+ manera].

En cuanto a las construcciones analíticas, podemos decir que, de igual forma, dependerá del caso concreto que se pertinentice o no el rasgo [+espacialización]. Son estas las construcciones típicamente semilocales y, si llevan actualizado el rasgo [+ espacialización] necesitarán específicamente un actante local, aunque -como ocurría con los de desplazamiento- no con el mismo gradiente que uno sin el rasgo [+modo de acción]. Según el juego de los rasgos, pues, se necesitará, o no, específicamente de un actante local.

En las construcciones que tienen un doble empleo, analítico y sintético ("estar colgado"/"colgar"), la diferencia semántica que es posible encontrar -cuando la forma sintética no tiene actualizado el rasgo [+ causa]- es, como en ocasiones anteriores, debida al "balanceo" de sus rasgos: el rasgo [+ espacialización] será más representativo en la forma analítica que sintética, y el rasgo [+ modo de acción] será más representativo en la forma sintética que analítica. K.Zimmer (1971) senala una distinta función de las expresiones analíticas y sintéticas: mientras las primeras tienen una funcionalidad claramente descriptiva, las segundas funcionan designativamente. Un sintagma sufijado será un medio para la designación de ciertos contenidos, que refieren no a través de una descripción, sino de la identificación inmediata. La utilización de uno u otro esquema lingüístico vendrá determinada por el marco co(n)textual en el que el intercambio comunicativo tiene lugar (Vera, 1987: 107). Así pues, los procesos de sufijación del verbo llevan acarreados una pérdida de contenido espacial y un aumento del modo de acción, aunque desde una perspectiva noemática es imprescindible la señalización -como expone Talmy- de estos contenidos.

En cuanto a los verbos de desplazamiento, ya sabemos que es posible deslindar semilocativos de locativos direccionales por los rasgos [+dirección] y [+ modo de acción], ya que estando los dos presentes en los dos tipos de verbos, la presencia funcional de uno u otro hace posible distinguirlos. De igual forma, los procesos de recategorización suponen la no relevancia del rasgo que era pertinente y la relevancia del rasgo que era no pertinente. Los dos rasgos siempre se darán en relación inversamente proporcional. Metalingüísticamente, y por mera convención, denominaremos a estos rasgos cuando no son relevantes sintáctico-semánticamente [+desplazamiento] y [+manera]. Es decir, un verbo locativo direccional se definirá, al menos, por los rasgos [+espacialización], [+dirección] y [+ manera], y uno semilocativo por [+espacialización], [+desplazamiento] y [ +modo de acción]. Es evidente que locativos y semilocativos se pueden diferenciar entre ellos por la manera y el modo de su acción espacial respectivamente, pero en esos detalles no vamos a entrar, es decir, en la diferencia entre "conducir" y "volar", por ejemplo, ya que tiene más relación con problemas instrumentales y referenciales que con aspectos propiamente sintáctico-semánticos. Por otra parte, es la ausencia funcional del rasgo [+ modo de acción] lo que hace que los verbos direccionales necesiten un gerundio, por ejemplo, para expresar lo que Talmy entiende por "manner".

El rasgo [ + causa] también puede estar lexicalizado en el verbo, y ello tanto con verbos de desplazamiento como con estativos. Ya señalamos igualmente las particularidades sintáctico-semánticas de este rasgo. Debemos añadir además que la actualización de este rasgo de causa acarrea que el agente deba ser conceptualizado como 
[+ animado] -y generalmente como [+ humano]-. Igualmente sabemos ya que en los direccionales el sujeto agente de la causa puede sufrir el mismo movimiento que la figura o no, lo que señalaremos con el rasgo [+ compañía].

Según Talmy, en muchos casos, la forma verbal singular puede ser manifiesta con o sin la idea incorporada de movimiento (abstracto). Más bien, lo que ocurre es que estos verbos, semilocativos o recategorizados como tales, pueden ser recategorizados sin el rasgo [+espacialización], con lo cual sólo se predica una manera o modo de acción.

B) Motion + Path. El verbo expresa tanto el rasgo [+espacialización] como el locativo (entendido tanto como marca casual, en su función relacionante de espacializador, como expresión locativa). Talmy señala que si la manera o la causa (no homologables con los rasgos por nosotros caracterizados) son expresadas en la misma frase, debe ser de forma independiente, generalmente en forma de gerundio. Evidentemente este rasgo no afectará a los semilocativos, que llevan actualizado el rasgo [+modo de acción] y no necesitan ver completada su "manera espacial".

En la incorporación del locativo debemos hacer diversos apartados: aquellos verbos como "atravesar", "sobrevolar", etc., que llevan lexicalizada la marca casual, y otros como "enmarcar" con lexicalización de la expresión localizadora y que sí responden perfectamente a este esquema propuesto por Talmy. Unos y otros los entenderemos actualizados con el rasgo [+ satélite], y en la representación que de ellos podamos hacer los diferenciaremos con [+satélite] y [+ satélite-base]. Sin embargo, ya señalamos que cuanto más complejo sea el proceso de amalgama propuesto (como es el caso de la incorporación de toda la expresión locativa) el rasgo [+espacialización] tendrá menor intensidad, y si a ello añadimos la posibilidad de actualización del rasgo [+modo de acción] comprobamos la poca representatividad que pueden llegar a tener estos verbos como predicados espaciales. Sin embargo, en un esquema noemático general de la espacialización creo necesario e imprescindible considerarlos.

Podemos encontrarnos con otro tipo de construcciones en las que la expresión localizadora no es que esté amalgamada como satélite sintético al verbo, sino que la base está implícita. Ya sabemos que toda enunciación está localizada, pero no toda enunciación enunciada, sin embargo, en muchas ocasiones, esta localización del enunciado puede estar presupuesta co(n)textualmente. Así:

¿Has subido el paquete?

Sí, sí to he subido.

Los lugares Ubi que articulan las localizaciones Unde-Quo del ejemplo están dados co(n)textualmente.

Pero no es este el tipo de localización implícita al que queremos aludir, sino a la localización deíctica. "Traer" y "venir", por ejemplo, suponen una localización implícita de los términos Unde-Quo, según el ámbito local en que se encuentran los actantes del enunciado. Otro tipo de verbos también pueden desarrollar un cierto contenido deíctico debido a la "localización propia" de los actantes, que determinará el conocimiento de su ubicación, así "emigrar", "inmigrar", "exportar", etc.

Hay un conjunto de verbos, tanto estativos como direccionales, que pueden tener uno, al menos de sus términos base implícito, y no nos referimos a los casos en los que el término Unde es conocido porque coincide con el del sujeto, está a la vista, tiene una localización propia o simplemente porque, como en "meter", es irrelevante -salvo especificaciones-, sino a aquellos casos en los que la base Unde o Quo está implícita discursivamente debido a las particularidades específicas del movimiento, más 
concretamente, debido al tipo de coordenadas en que éste se desdarrolla o la ubicación en que se efectúa. Así, "tumbar" o "levantar" -los dos con el rasgo [+ causa]- pueden presuponer el primero una posición y el segundo un término Quo (Unde está dado como irrelevante por lo general) por tratarse de la dimensión espacial vertical, que es universal, es decir, con "levantar", según el objeto figura que se localice, tendrá un lugar propio, no dado -por lo general- por irrelevante o conocido contextualmente debido a la convertibilidad objeto >lugar, y el término Quo de este movimiento se sabe que es en la dimensión vertical; este Quo, igualmente, puede tener una localización propia, debido al sujeto agente o al 'abajo' del tipo de objeto figura, o puede también ser especificada. Con "erguir" o "tumbar" se trata de un proceso parecido, pues "erguir" supone una posición en dimensión vertical, que es universal y según el tipo de discurso, el objeto y agente, y el tipo de situación, quedará perfectamente especificada la posición vertical de que se trate; con "tumbar" es un proceso similar pero a la inversa: el objeto está dado como en posición vertical, y en las construcciones causales con este verbo se trata de situarlo en una posición no vertical. Especificaresmos esta característica, asimilable al componente deíctico, con el rasgo [ + base], con lo cual queremos decir que, debido a la dimensión en que se desarrolle la localización, no tiene por qué especificarse la localización, pues está dada en el verbo.

En algunas ocasiones parecerá difícil delimitar si se trata de un movimiento o de un cambio de posición, caso de "levantar" y "acostar", ello ocurre cuando son causales y el estativo señala un movimiento con unas características peculiares en cuanto a la posición de la figura; sin embargo, creemos que unos y otros se diferencian porque "levantar" predica un desplazamiento y "acostar" un movimiento con unas determinadas características para la nueva posición, pero la manera de hacerlo no importa mucho; prueba de ello puede ser la capacidad de articularse "levantar" con expresiones direccionales (desde, hasta, etc.), cosa que no es posible con "acostar". Sin embargo, caracterizaremos a estos verbos como direccionales o estativos dependiendo de que cada caso concreto -según el tipo de objeto que sea la figura y su ambitalización con el enunciador- funcione de una forma u otra, según se considere tener unas posiciones propias o no (generalmente, por ello, también actualizan el rasgo [+base])y según se considere un desplazamiento o no: "levanta la figura" (está tumbada)/ "levanta la pelota del suelo".

Otro aspecto funcionalmente interesante es el caso de determinados verbos direccionales que suponen entrada efectiva en un lugar, y lo articulan con la dimensión interior, es decir, con un término específicamente Ubi y no Quo. "Meter", por ejemplo, supone un desplazamiento o cambio de lugar, pero selecciona para ese desplazamiento la dimensión interior interna, de tal forma que el término Unde está dado contextualmente como lo exterior. Si el caso de verbos como éste es interesante es porque pueden señalar el término Quo con "en" (al igual que puede ocurrir en latín, no así cuando la dimensión interior que selecciona es la exterior), funcionando por tanto actancialmente. En verbos de este tipo es muy importante la reconstitución esquemática de la escena espacial, pues según se trate de una ubicación como Quo o como Ubi, su papel de interviniencia con el predicado será diferente y puede prestarse a confusiones si el término Quo está dado contextualmente. El aspecto que queremos señalar con esto es que determinados verbos seleccionan un tipo específico de dimensión con la que operar, así los ya vistos la interior, y la mayoría de los que actualizan el rasgo [+base] la vertical, y esto será un dato importante para nuestro análisis: la selección de la dimensión con la que pueden operar ( $y$ esto es a lo que Talmy parece estar refiriéndose con este punto, ya que es lo que selecciona un tipo determinado de formas casuales y marcas casuales. En definitiva este es un aspecto muy complejo, pues depende de la situación e intencionalidad que, en muchas 
ocasiones, se actualicen o no los dos términos del desplazamiento, por ejemplo.

Los verbos locativos direccionales, por otra parte, pueden especificar la manera mediante un gerundio. En cuanto a la causa -tal y como nosotros la entendemos-, sabemos que puede estar presente con cualquier tipo de verbos.

El último aspecto con el que queríamos cerrar este punto es recordar algo ya dicho: el proceso de síntesis en la amalgama de los satélites en el complejo verbal lleva consigo una pérdida en sus valores descriptivos, lo que es decir espaciales.

C) Motion + Figure. Ya hemos mọstrado, por el rasgo [+ causa], que la figura puede no ser el sujeto de la localización; aquellos verbos locativos que no tienen este rasgo determinan que la figura es el objeto y agente de la localización. Talmy señala como ejemplo de esta amalgama algunas lenguas (atsugewi, entre otras) en las que el complejo verbal especifica determinado tipo de figura (Talmy, 1985: 72-74), cosa que no ocurre en español. Las referencias sobre la figura en español no sólo son las provenientes de la actualización del rasgo [+causa], como veremos más adelante, también es posible encontrar determinados verbos con objeto interno que funciona como figura de una localización.

D) Aspect. El aspecto, en tanto modelo de distribución de la acción a través del tiempo, es un contenido muy importante incorporado al semismo verbal. El aspecto, perfectivo, puntual, repetitivo, por ejemplo, permite caracterizar el semismo verbal de determinados verbos de desplazamiento, como "volver", "venir", "entrar", "llevar", etc.

Los otros tipos de rasgos que incorpora Talmy en su esquema de amalgama verbal ya los hemos ido interrelacionando a través de nuestra exposición, que sólo pretende referirse a los verbos con el sema [+espacialización].

\subsection{Verbos de percepción.}

Fillmore (1968) distingue dos tipos de verbos de percepción física: estativos y activos ("ver"/"mirar"). Los primeros requieren un sujeto en caso 'dativo', para los segundos el sujeto es 'agente'. Rogers (1976) entiende que es posible trasponer la distinción "ver"/"mirar" a los cinco tipos de percepciones físicas según esa percepción sea accidental o intencionada. El problema, sin embargo, que queremos plantear es la caracterización semántica del objeto de esos verbos.

Gruber (1967) piensa que "to see" debe analizarse en estructura profunda como verbo de movimiento, basándose en que este verbo puede funcionar como intransitivo con sintagmas preposicionales encabezados con into, through, etc. Cano Aguilar (1981) señala que en español esto no ocurre con "ver", sino con "mirar", el cual toma entonces un valor locativo direccional: "mirar hacia X".

"Estos empleos intransitivos de mirar parecen justificarse en virtud de un empleo 'absoluto' del verbo, por el cual pasa de una acción que apunta a un objeto, a la acción en sí misma; si se quicre precisar y concretar de nuevo la acción, se recurre a un sintagma de claro carácter 'locativo'. Incluso csta interpretación podría valer para los objetos directos de mirar, en su empleo transitivo. El complemento de mirar, fuera objeto directo o no, indicaría el 'lugar' sobre el que se ejerce la acción de "mirar". Esto podría venir apoyado por las posibles paráfrasis de las frases que integra este verbo: mirar una cosa o mirar hacia una cosa pueden interpretarse como "dirigir la mirada hacia una cosa"; sólo que en la segunda frase el valor locativo aparece explícilo. Por otro lado, mirar excluye a veces objetos en los que no aparece un rasgo 'localivo', cosa que no ocurre con ver: *miró que Juan llegaba, "a Juan lo he mirado muy viejo (en cambio: vio que Juan llegaba, veo muy viejo a Juan). Al exigir que su objeto indique la dirección o el punto de referencia de la "mirada", este verbo no se consiruye con oraciones o predicados referidos al objcto, como ocurre con ver." (Cano Aguilar, 1981: 153). 
Para Rogers (1976) es posible encontrar formas sintácticamente no estativas en los cinco tipos de verbos de percepción física, pareciendo actuar sus sujetos como agentes. Sin embargo, como expone Cano Aguilar, sólo es con "mirar" con el que el objeto directo puede interpretarse con valor 'locativo' y aparecer en sintagmas preposicionales con ese valor. Por tanto, los objetos del resto de verbos activos de percepción física sólo podrán interpretarse, en el sentido de Fillmore, como causas o estímulos de la percepción.

Así pues, entendemos que como la gente emplea el lenguaje con el verbo "mirar" es de una forma totalmente diferente al resto de verbos de percepción física. Extremando las propuestas de Cano Aguilar podemos llegar a plantear si la diferencia entre estructuras transitivas e intransitivas con "mirar" no obedece simplemente al contenido sémico de la marca casual (hacia), siendo su objeto en todos los casos un actante de carácter locativo (como ocurre con "ir a Madrid"/"ir hacia Madrid"), sin embargo, la posibilidad de conversión por LO rompe la propuesta. El uso del verbo "mirar" es entendido como un desplazamiento, en este caso un desplazamiento perceptivo en el que "la mirada" es la figura. Como todo verbo de desplazamiento, entonces, es entendido noemáticamente como dos ubicaciones, pero con ciertas peculiaridades: en primer lugar, el término Unde viene dado por la posición del sujeto, ya que la 'mirada' siempre se encuentra en el sujeto, si no se conoce su localización se especifica como término Unde. El término Quo no tiene por qué ser un lugar, pero gracias a la convertibilidad objeto/lugar, en tanto que son los objetos los que determinan los lugares, es posibie entender ese objeto como si de un lugar se tratara. Debido al aspecto del verbo "mirar", en tanto que siempre que se actualiza es cumplido, no es posible predicar la localización del desplazamiento, por tanto no puede ser recategorizado como semilocativo con Qua-2, ni puede construirse localmente con expresiones Qua-2. Sin embargo sí puede combinarse con ciertas expresiones que parecen Qua-2 por la forma, pero que funcionalmente actúan como localizaciones Ubi que articulan el término Unde ("por la ventana", "por la mirilla", etc.,), es decir, como marcos de salida del desplazamiento. Es muy importante también que no confundamos la localización de la acción con la articulación del término Ubi de llegada, ya que supondrán una distinta interviniencia.

\subsection{Acusativo partitivo.}

Son muy interesantes ciertas construcciones en las que verbos como "golpear", "herir", "morder", pueden insertarse en dos tipos de estructuras que responden a la siguiente esquematización según Cano Aguilar (1981: 63-65): V + OD ("parte del cuerpo") + OI/ $\mathrm{V}+=\mathrm{D}$ (el Ol de la otra estructura) + SPrep ("parte del cuerpo", con valor locativo): "me quemó la pierna"/"me quemó en la pierna". Se suele decir que en las estructuras directas se presupone que lo quemado fue toda la pierna, mientras que la construcción con locativo presenta una interpretación 'partitiva', lo quemado fue sólo una parte.

Cano Aguilar (1981: 64-65) recuerda igualmente la polémica generativista según la cual los defensores de una gramática de casos postularían un mismo caso locativo en la estructura profunda de ambas frases, dándose las diferencias únicamente en estructura superficial, mediante nociones como 'foco' del mensaje.

Si consideramos la estructura local de estas construcciones vemos que la expresión locativa Ubi nos especifica la base local y la relación de espacialización de la marca casual, sin embargo la figura y el tipo de predicación que se da es más complejo determinarlo. Todos estos verbos ('golpear'/'quemar'/'herir'/'morder'/'pellizcar', etc.) 
pueden ser parafraseados en forma analítica ("dar un golpe, un mordisco", etc.), siendo el objeto inherente la figura de la localización, es por ello que cuando vienen manifestados en forma sintética expresan un modo de acción. Igualmente este tipo de verbos tendría el rasgo [+ causa] que venimos comentando en apartados anteriores al no ser la figura el agente-causa de la localización. Por tanto, estos verbos, contradiciendo nuestras palabras de apartados anteriores, demuestran que sí es posible en español la amalgama verbal "predicado/figura", y no sólo con el caso excepcional de "mirar". Por otro lado, Hopper \& Thompson (1980: 262-263) señalan quẹ el carácter partitivo del objeto es un rasgo universalmente asociado a los verbos intransitivos, $o$, al menos, a alguna señal de transitividad reducida.

Señalamos en páginas anteriores que en lexicalizaciones como "sazonar" ('poner sal en'), donde el verbo está formado a partir de la figura, el lexema resultante carece del rasgo [+ espacialización], y simplemente se predica una manera o modo de acción, pero no una espacialización. Una explicación similar se puede dar con este conjunto de verbos: en las estructuras directas simplemente se predica una manera o modo de acción pero nunca funciona el rasgo [+espacialización]. Sin embargo, el conjunto de verbos que venimos considerando pueden ser recategorizados con la entrada en funcionamiento del rasgo que denominaremos [ + figura] que pertinentiza un rasgo [ + espacialización]. Este tipo de verbos puede ser categorizado de dos maneras: en cuanto manera de acción que afecta a un objeto o en cuanto manera de acción que afecta a un lugar; la convertibilidad objeto/lugar explica la posibilidad de expresión de una u otra manera. Igualmente, que el objeto/lugar sea una parte del cuerpo humano es una característica determinante. Cuando el modo de acción afecta a la consideración de un objeto, no es visto como relevante el objeto interno, necesario, como figura, para la localización.

Por la recategorización semilocativa que pueden realizar estos verbos, el complemento de lugar que expresan tiene un grado de interviniencia -en el sentido de Savary (1984)- que no es ni plenamente actancial como con los verbos locativos, ni plenamente circunstancial. Hasta ahora habíamos delimitado cuatro tipo de actancialidades locales según su vinculación sémica con el predicado: el circunstante enmarcador, el circunstante, el actante local y el actante semilocal, este último, propio de los verbos semilocales, era exigido específicamente por el verbo en cuestión, aunque la actancialidad de los verbos locativos parecía más representativa que la de éstos. En los casos que venimos comentando, las expresiones localizadoras serían allegables a las de los verbos semilocativos, pues se trata de verbos semilocativos también, pero, a diferencia de los primeros, los entendemos como recategorizaciones a partir de verbos localizables, es por ello que, dentro de este grupo tercero, parezcan menos actanciales que los actantes locativos de los verbos propiamente semilocativos.

Noemáticamente pues, estos verbos manifiestan dos maneras de categorizar la realidad, o bien simplemente como modo de acción, o bien considerando la incidencia espacial. En cuanto a la dualidad parte/todo, que tradicionalmente se ha venido considerando como la diferencia que permitía distinguir una expresión directa de una locativa, es un aspecto deducible del razonamiento expuesto con anterioridad: en "muerdo la pierna", 'la pierna' es neutralizada en cuanto a su extensión o totalidad, ya que se considera al objeto en su conjunto como modificado por determinado modo de acción. Sin embargo, en "me mordió en la pierna", noemática es conceptualizado como 'dar un mordisco en la pierna', y, evidentemente, depende del agente causante ('hombre' o 'tiburón', por ejemplo) que el mordisco se localice en una extensión u otra de la pierna, pues ya no se trata del objeto afectado por la acción de morder, sino de la localización de un mordisco. 
Sintagmáticamente sólo se pueden combinar con Ubi-1; los que no actualizan el rasgo [+incidencia espacial] también se pueden combinar con Ubi-2. Determinadas construcciones con Qua-1 se pueden neutralizar como Ubi-2 (actante semilocativo) en predicaciones espaciales: "me pellizcaba por todas partes".

\subsection{Reformulaciones.}

Tras lo visto, y antes de pasar a efectuar el esquema al que hemos llegado en nuestros planteamientos sobre la localización, hemos de señalar algunos aspectos que consideramos de fundamental importancia.

Los verbos direccionales, especialmente los que tienen el rasgo [+causa], por la convertibilidad objeto > lugar, pueden neutralizar el término Quo con un destinatario (el término Unde con un destinador es mucho más raro): "lo lanzó al suelo" / "lo lanzó a Pedro".

Queremos insistir, de nuevo, en los límites un tanto difusos entre los verbos de posición con el rasgo [+ causa], verbos de posición o de modificación de posición, y los verbos direccionales que sólo dinamizan uno de los términos Unde-Quo. En los dos casos se hace constancia resultativa de una nueva posición, pero mientras que en los posicionales no interesa el movimiento, sino, si acaso, la manera del objeto en la nueva posición, en los direccionales sí se predica un tipo de movimiento, interesa el desplazamiento. Aún así, es posible encontrar verbos que pueden tener un doble funcionamiento ("levantar").

Hemos repetido, incansablemente, que la enunciación siempre está localizada, pero no la enunciación enunciada. Sin embargo, en los casos en que noemáticamente es exigible, puede lingüísticamente no estarlo debido a determinaciones contextuales; así, por ejemplo, hay muchos verbos direccionales ("girar", "meter", etc.) que no dinamizan uno de sus términos Ubi por impertinente, o porque es deducible del contexto, o por las dos razones. 
Qua-1. Circunstante (Qua-2 se neutraliza)

Ubi-2. Circunstante.

Ubi-1. Circunstante enmarcador.

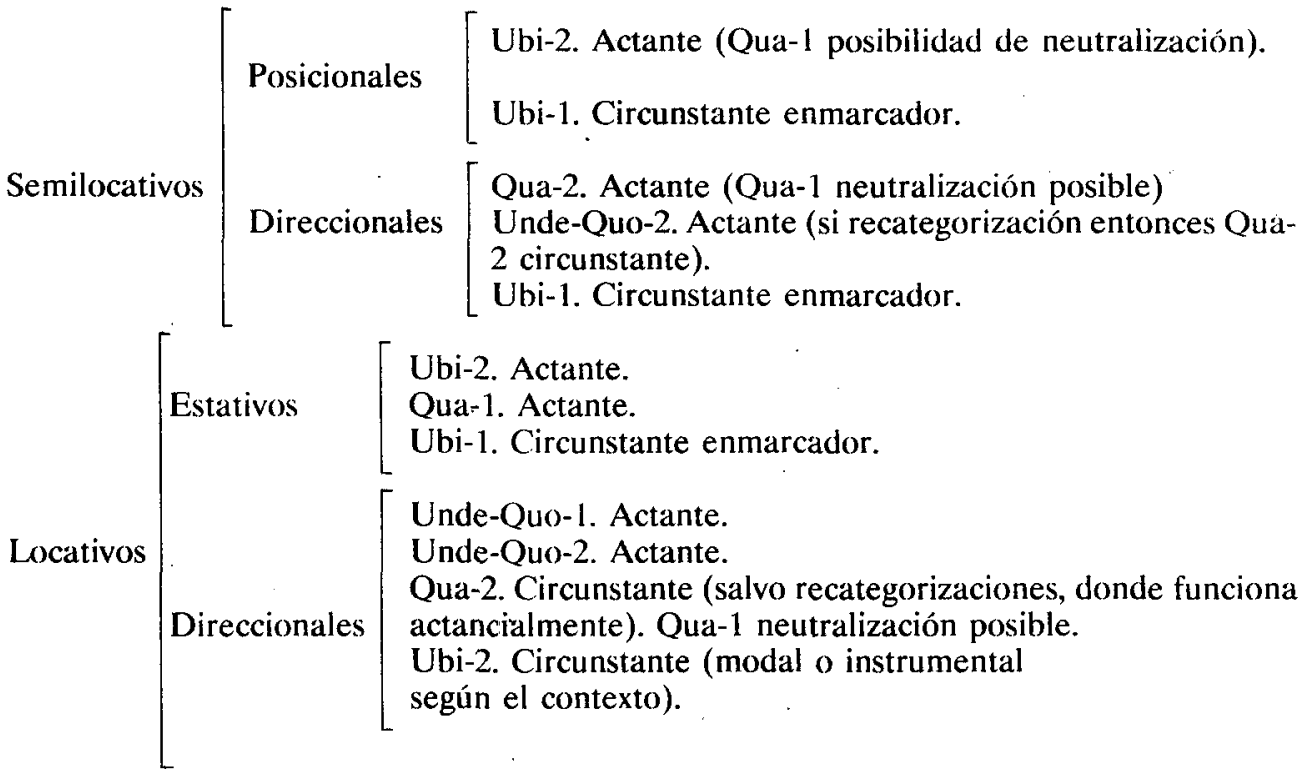

\section{Referencias bibliográficas}

Alarcos García, E. (1980): Estudios de Gramática Funcional del Español, Madrid, Gredos. Báez San José, V. (1988): Fundamentos Críticos de la Gramática de Dependencias, Síntesis, Madrid.

Boons, J.P. (1985): "Préliminaires à la classification des verbes locatifs: les compléments de lieu, leurs valeurs aspectuelles", Linguistacae Investigationes, IX-2, pp: 195-267.

Boons, J.P. (1988): "La notion sémantique de déplacement dans une classification syntaxique des verbes locatifs", Langue Française, 76, pp: 5-40.

Boons,J.P.-Guillet,A.-Leclére,Ch. (1976): La structure des phrases simples en français. Constructions intransitives, Droz, Genève-Paris.

Bosque, I. (1983): "Dos notas sobre el concepto de "suplemento" en la gramática funcional", Dicenda, 2, pp: 147-156.

Busse,W-Dubost,J.P. (1977): Französisches Verblexikon, Klett-Cotta.

Buyssens, E. (1975): Les catégories grammaticales du français, Univ. de Bruxelles.

Cano Aguilar, R. (1981): Estructuras sintácticas transitivas del español actual, Madrid, Gredos.

Cifuentes Honrubia, J.L. (1989): Lengua y espacio. Introducción al problema de la deúxis en español, Universidad de Alicante.

Contreras, H. (1983): El orden de palabras en español, Cátedra, Madrid.

Coseriu, E. (1978): El hombre y su lenguaje, Madrid, Gredos.

Coseriu, E. (1981): Principios de semántica estructural, Madrid, Gredos.

Dervillez-Bastuji, J. (1982): Structures des relations spatiales dans quelques langues naturelles, 
Genève, Droz.

Dik, S.C. (1981): Gramática Funcional, SGEL, Madrid.

Engel,U.-Schumacher,H. (1976): Kleines Valenzlexikon deutscher Verben, Forschungsberichte

des Instituts für deutsche Sprache Mannheim, 31, Tübingen.

Fillmore, Ch.J. (1968): "The case for case", in E.Bach-R.T.Harms (eds.): Universals in Linguistic Theory, New York, Rinehart \& Winston, pp: 1-88.

Fillmore, Ch.J. (1985): "Frames and the semantics of understanding", Quaderni di Semantica, 12, pp: 222-254.

Fillmore, Ch.J. (1986): "U-semantics, second round", Quaderni di Semantica, 13, pp: 49-58. Fraser, P. (1974): The verb-particle combination in English, New York, Academic Press. Greimas,A.J.-Courtés,J. (1982): Semiótica. Diccionario razonado de la teoria del lenguaje, Madrid, Gredos.

Gruber, J.S. (1967): "Look and See", Language, 43-4, pp: 937-947.

Gutiérrez Araús, M.L. (1978): Estructuras sintácticas del español actual, Madrid, SGEL.

Gutiérrez Araús, M.L. (1987): "Sobre la transitividad preposicional en español", Verba, 14, pp: 367-381.

Happ, H. (1977): "Syntaxe latine et théorie de la valence. Essai d'adaptation au latin des théories de Lucien Tesnière", Les Etudes Classiques, 45, pp: 337-366.

Happ, H. (1978): "Théorie de la valence et enseignement du français", Le français moderne, 46-2, pp: 97-134.

Heger, K. (1976): Monem, Wort, Satz und Texte, Max Niemeyer Verlag, Tübingen.

Helbig,G.-Schenkel,W. (1969): Wörterbuch zur Valenz und Distribution deutscher Verben, Leipzig.

Herbst, T. (1984): "Adjective complementation: A Valency Approach to making EFL Dictionaries", Applied Linguistics, 5, pp: 1-11.

Hopper,P.J.-Thompson,S.A. (1980): "Transitivity in grammar and discourse", Language, 562, pp: 251-299.

Lakoff, G. (1971): Irregularity in Syntax, Holt, Rinehart \& Winston.

Lakoff, G. (1987): Women, Fire and Dangerous Things, University of Chicago Press, Chicago.

Langacker, R.W. (1988): "Mouvement abstrait", Langue Française, 76, pp: 59-76.

Lipka, L. (1976): "Topicalization, case grammar and lexical decomposition in English", Archivum Linguisticum, II-5/7, pp: 118-141.

Martinet, A. (1984): Gramática funcional del francés, Ariel, Barcelona.

Martínez García, H. (1986): El suplemento en español, Madrid, Gredos.

Matisoff, J. (1973): The Grammar of Lahu, Berkeley, University of California Press.

McCawley, J.D. (1976): "¿De dónde proceden los sintagmas nominales?", in Sánchez de Zavala (ed.): Semántica y sintaxis en la lingüística transformatoria, Alianza, Mạdrid, pp: 232-258.

Moreno Cabrera, J.C. (1987): Fundamentos de sintaxis general, Síntesis, Madrid.

Ramón Trives, E. (1975): "En torno a los conceptos de transitividad, complementación y circunstancia desde la teoría actancial y causal: problemas hispánicos", Anales Universidad de Murcia, XXV-3/4, pp: 91-121.

Ramón Trives, E. (1982): Estudios sintáctico-semánticos del español. La dinámica interoracional, Murcia, Godoy.

Rogers, A. (1976): "Tres tipos de verbos de percepción física" in Sánchez de Zavala (ed.): Semántica y sintaxis en la lingüística transformatoria, Alianza, Madrid.

Rojo, G. (1983): Aspectos básicos de sintaxis funconal, Málaga, Agora.

Rojo, G. (1985): "En torno a los complementos circunstanciales", Lecciones del I y II curso 
de lingüística funcional (1983 y 1984), Universidad de Oviedo, pp: 181-191.

Rosch, E.M. (1973): "On the internal structure of perceptual and semantic categories", in

T.E.Moore (ed.): Cognitive Development and the Acquisition of Language, New York,

Academic Press, pp: 111-144.

Rosch, E.M. (1977): "Human categorization", in N.Warren (ed.): Studies in Cross-cultural

Psychology, I, New York, Academic Press, pp: 1-49.

Rothenberg, M. (1986): "La notion de valence et la semantique verbale", Actes du XVII

Congrès International de Linguistique et Philologie Romanes (Aix-en-Provence, 29 Aout-

3 septembre 1983), Aix en Provence, IV, pp: 285-295.

Savary, R. (1984): Ordre langier, champ spatial et emplois figurés. Prépositions, cas et verbs en allemand et en français, Linguistische Arbeiten, 143, Max Niemeyer Verlag, Tübingen.

Schönfeldt,A-Zander-Lüllwitz,B. (1976): "Überlegungen zur fakultativen Ergänzung", in F.Debus-J.Hartig (eds.): Festschrift für Gerhard Cordes zum 65 Geburstag, Neumunster, II, pp: 308-321.

Somers, H.L. (1984): "On the Validity of the Complement-Adjunct distinction in Valency Grammar", Linguistics, 22, pp: 507-530.

Steinitz, R. (1969): Adverbial-Syntax, Berlin, Akademie-Verlag, Studia Grammatica X.

Talmy, L. (1975): "Semantics and Syntax of motion", in J,Kimball (ed.): Syntax and Semantics, 4, New York, Academic Press, pp: 181-238.

Talmy, L. (1983): "How languages structures space", in H.L.Pick-L.P.Acredolo (eds.): Spatial orientation, New York, Plenum Press, pp: 225-282.

Talmy, L. (1985): "Lexicalization patterns: semantic structure in lexical forms", in Th.Shopen (ed.): Language Typology and syntactic descriptions, New York, Cambridge University Press, pp: 57-149.

Tesnière, L. (1976): Elèments de syntaxe structurale, Klincksieck, Paris.

Vandeloise, C. (1988): "La préposition à et le principe d'anticipation", Langue Française, 76, pp: $77-111$.

Vera, A. (1987): Aspectos sintáctico-semánticos en la sufijación, Universidad de Murcia. Vernay, H. (1974): Essai sur l'organisation de l'espace par divers systèmes linguistiques, Wilhelm Fink Verlag, München.

Zimmer, K. (1971): "Some general Observations about Nominal Compounds", Working Papers on Language Universals, Standford University, pp: 1-21. 